\title{
AN ADVANCED PROCEDURE FOR THE QUANTITATIVE RISK ASSESSMENT OF OFFSHORE INSTALLATIONS IN EXPLOSIONS
}

(DOI No: 10.3940/rina.ijme.2017.a2.394)

S J Kim, The Korea Ship and Offshore Research Institute (Lloyd's Register Foundation Research Centre of Excellence) at Pusan National University, Korea, J M Sohn, Pukyong National University, Korea and J K Paik*, Pusan National University, Korea and University College London, UK

\section{SUMMARY}

Hydrocarbon explosion and fire are typical accidents in the offshore oil and gas industry, sometimes with catastrophic consequences such as casualties, property damage and pollution. Successful engineering and design should meet both functional requirements associated with operability in normal conditions and health, safety, environmental and ergonomics (HSE\&E) requirements associated with accidental and extreme conditions. A risk-based approach is best for successful design and engineering to meet HSE\&E requirements. This study aimed to develop an advanced procedure for assessing the quantitative risk of offshore installations in explosions. Unlike existing industry practices based on prescriptive rules or qualitative approaches, the proposed procedure uses an entirely probabilistic approach. The procedure starts with probabilistic selection of accident scenarios. As the defining components of risk, both the frequency and consequences associated with selected accident scenarios are computed using the most refined technologies. Probabilistic technology is then applied to establish the relationship between the probability of exceedance and the physical values of the accident. Acceptance risk criteria can be applied to define the nominal values of design and/or level of risk. To validate and demonstrate the applicability of the proposed procedure, an example of its application to topside structures of an FPSO unit subjected to hydrocarbon explosions is detailed. The conclusions and insights obtained are documented.

\section{ABBREVIATIONS}

$\begin{array}{ll}\text { ALARP } & \text { As Low As Reasonably Practicable } \\ \text { CFD } & \text { Computational Fluid Dynamics } \\ \text { CV } & \text { Control Volume } \\ \text { DLF } & \text { Dynamic Load Factor } \\ \text { FE } & \text { Finite Element } \\ \text { FEA } & \text { Finite Element Analysis } \\ \text { FLACS } & \text { FLame ACceleration Simulator } \\ \text { FLNG } & \text { Floating Liquefied Natural Gas } \\ \text { FPSO } & \text { Floating, Production, Storage and Offloading } \\ \text { HSE\&E } & \text { Health, Safety, Environmental and } \\ & \text { Ergonomics } \\ \text { IP } & \text { Ignition Probability } \\ \text { LNG } & \text { Liquefied Natural Gas } \\ \text { NLFEM } & \text { Nonlinear Finite Element Method } \\ \text { SDOF } & \text { Single Degree of Freedom }\end{array}$

\section{NOMENCLATURE}

$A_{C V} \quad$ Minimum area around the leak $\left(\mathrm{mm}^{2}\right)$

$A_{\text {leak }} \quad$ Leak area $\left(\mathrm{mm}^{2}\right)$

$C \quad$ Cowper-Symonds coefficient (1/s)

E Elastic modulus (MPa)

I Ignition probability (-)

$\max . C V \quad$ Maximum size of $\mathrm{CV}\left(\mathrm{m}^{3}\right)$

$q \quad$ Cowper-Symonds coefficient

$V_{\text {gas }} \quad$ Gas cloud volume $\left(\mathrm{m}^{3}\right)$

$x \quad$ Leak rate $(\mathrm{kg} / \mathrm{s})$.

$\varepsilon_{f} \quad$ Fracture strain under static load (-)

$\varepsilon_{f d} \quad$ Fracture strain under dynamic load (-)

$\dot{\varepsilon} \quad$ Strain rate $(1 / \mathrm{s})$

$v \quad$ Poisson's ratio (-)

$\rho \quad$ Density $\left(\mathrm{kg} / \mathrm{m}^{3}\right)$

$\sigma_{Y} \quad$ Yield stress under static load (MPa)

$\sigma_{Y d} \quad$ Yield stress under dynamic load (MPa)

\section{INTRODUCTION}

A number of different types of accidental and extreme events can occur while ships and offshore installations are in service as shown in Figure 1 (Paik, 2015). Hydrocarbon explosion and fire are two of the most typical types of accidents associated with offshore installations, and they sometimes result in catastrophic consequences leading to casualties, property damage and pollution.

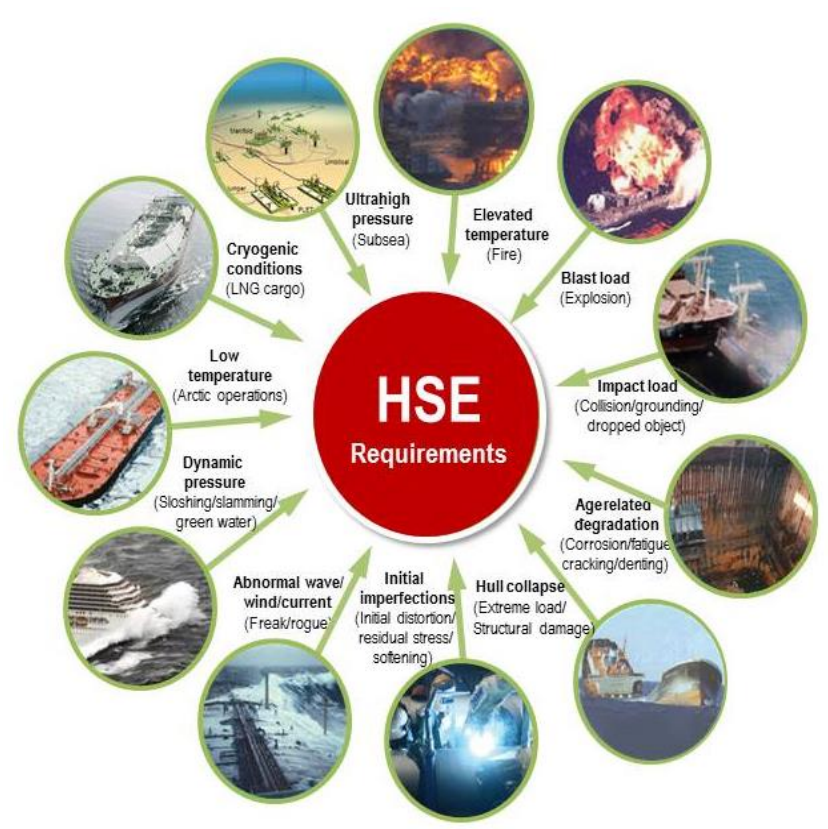

Figure 1: Different types of accidental and extreme events involving ships and offshore installations while in service (Paik, 2015) 
Successful engineering and design should meet not only functional requirements but also HSE\&E requirements. Functional requirements address operability in normal conditions, and HSE\&E requirements represent safe performance and integrity in accidental and extreme conditions. Normal conditions can usually be characterised by a solely linear approach, but more sophisticated approaches need to be applied to accidental and extreme conditions involving highly nonlinear responses as shown in Figure 2 (Paik et al., 2014). The risk-based approach is known to be the best method for successful design and engineering to meet the HSE\&E requirements against accidental and extreme conditions.

In the existing practices, methods for risk assessment are usually prescriptive (predefined or deterministic) (FABIG, 1996; API, 2006; ABS, 2013; DNVGL, 2014). Although they are useful when performing explosion risk assessment, a fully probabilistic approach takes centre stage and reduces uncertainties from human error (Czujko, 2001; Vinnem, 2007; NORSOK, 2010; Paik and Czujko, 2010; Paik, 2011; ISO, 2014; LR, 2014).

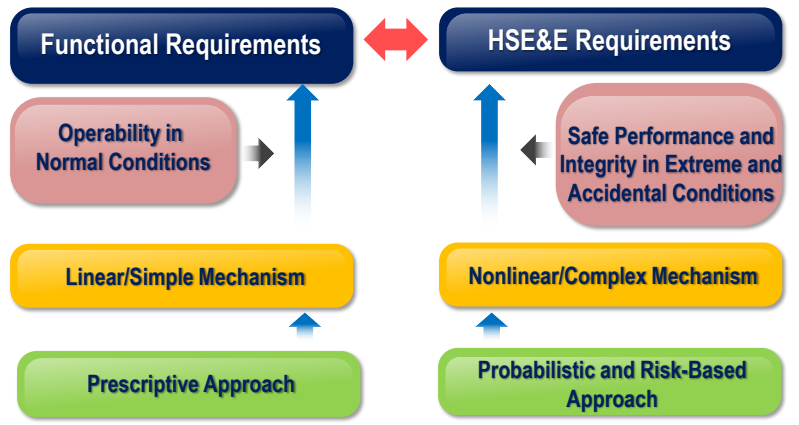

Figure 2: Paradigm change in engineering and design (Paik et al., 2014)

The aim of this study is to develop an advanced procedure for the quantitative risk assessment of offshore installations in explosions, taking advantage of an entirely probabilistic approach.

The proposed procedure starts with the selection of accident scenarios based on the probabilistic approach. Then, simulations are performed using CFD and NLFEM to calculate the structural consequences.

As risk is defined as the product of frequency and consequence, the probabilistic technology can further be applied to establish the relationship representing the probability of exceedance versus the physical values of the accident. Finally, acceptance risk criteria can be applied to define nominal values of design and/or the level of risk.

In the present study, an applied example to topside structures of a FPSO unit subjected to hydrocarbon explosions is shown in detail to validate and demonstrate the applicability of the proposed procedure.

\section{AN ADVANCED PROCEDURE FOR QUANTITATIVE RISK ASSESSMENT IN EXPLOSIONS}

In contrast to a prescriptive approach, the advanced procedure for risk assessment of explosions on offshore platforms proposed in this study uses an entirely probabilistic approach for reliable risk assessment in explosions.

Figure 3 presents the suggested procedure for quantitative risk assessment and management of an offshore installation against explosions.

In comparison with fires, hydrocarbon explosions can occur when a gas cloud combining with oxygen is ignited. Thus, gas dispersion must be considered before selecting explosion scenarios and simulations.

This procedure adopts a probabilistic approach to select gas dispersion and explosion scenarios. It can be divided into 11 steps defined as follows:

1) Selection of offshore structure type

2) Characterisation of topology

3) Selection of gas dispersion scenarios

4) Investigation of gas cloud characteristics

5) Selection of gas explosion scenarios

6) Investigation of blast loads

7) Calculation of gas explosion frequency

8) Definition of nominal explosion value

9) Nonlinear structural consequence analysis

10) Risk calculation

11) Decision making

To investigate the gas cloud characteristics, blast loads and structural response, this procedure adopts an experimental test and/or CFD and NLFEM. In addition, the actual blast loads are applied to structural consequence analysis in the procedure using the interface between CFD/experiment and NLFEM.

Finally, risk is calculated using the structural consequence and probability of explosion scenarios, and decision making is conducted with acceptance criteria based on ALARP risk.

\section{VALIDATION OF CFD AND FE MODELLING TECHNIQUES}

Before performing the CFD simulation and FEA, validations of modelling techniques are needed. In this part, comparisons of results between 'CFD and experiment', and 'FEA and experiment' respectively.

\subsection{VALIDATION OF CFD MODELLING}

Large-scaled explosion experimental tests were conducted by the Korea Ship and Offshore Research Institute at Pusan National University, Korea. 


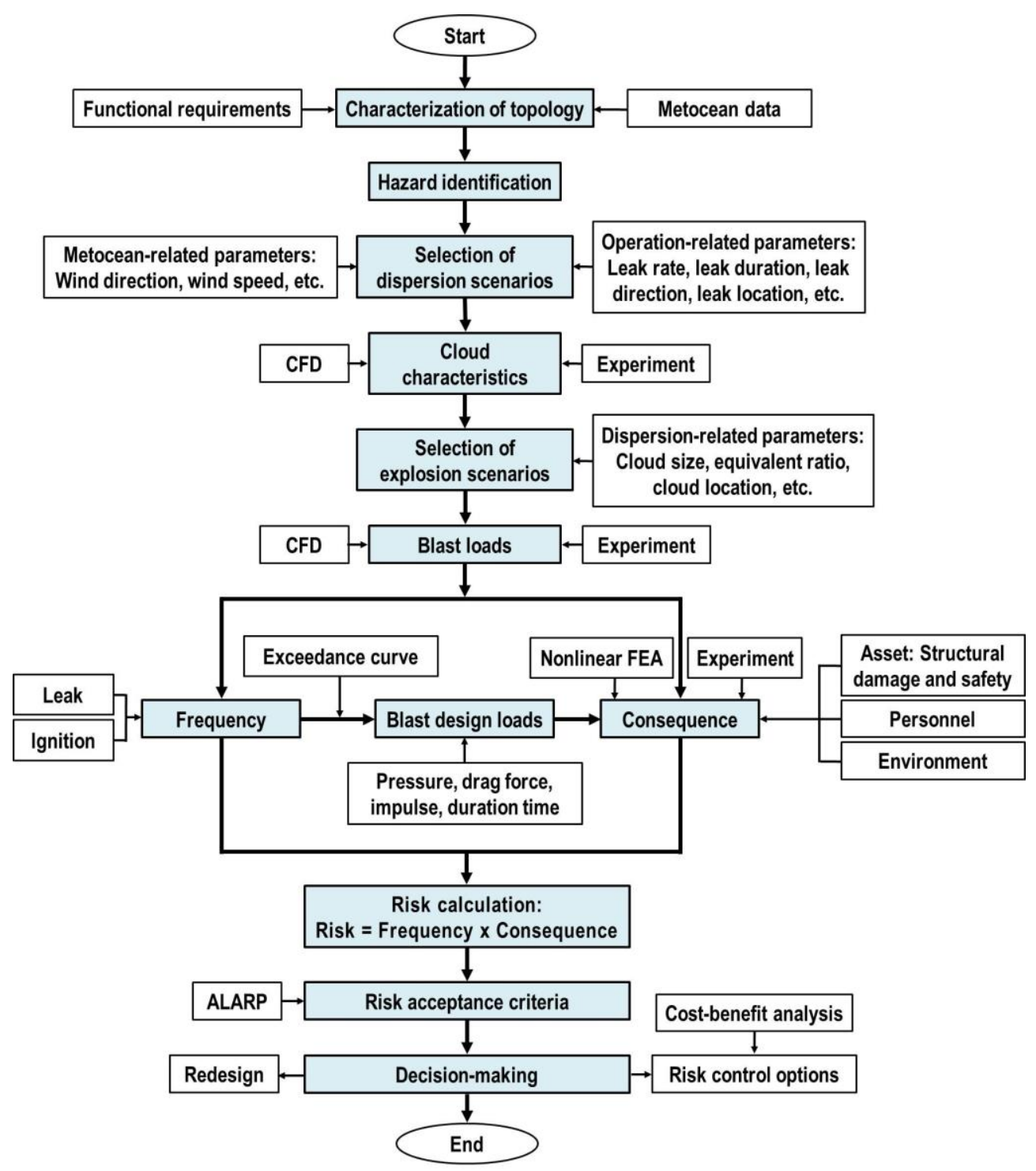

Figure 3: The advanced procedure for quantitative explosion risk assessment and management

Figure 4 shows target structure which is a module on offshore installation in the test and CFD simulation.

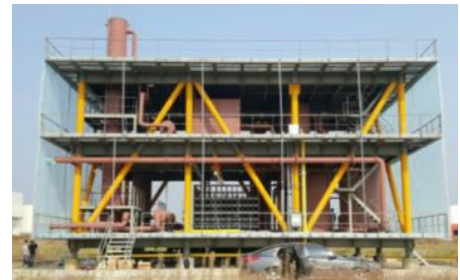

(a) Test model

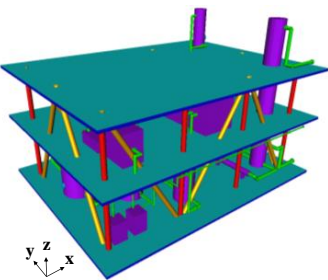

(b) CFD model
Figure 4: Target structures for validation of CFD simulation

Figure 5 presents the comparison of results of experiment and CFD simulation. From Figure 5(a), it can be seen that CFD modelling technique is in a good agreement with the test.
Also, Figure 5(b) which illustrates test versus simulated results for maximum overpressure shows that CFD modelling technique is proper. The limit of $\pm 30 \%$ for under- and over-prediction suggested by Pedersen and Middha (2012) are considered as values to be reasonable.

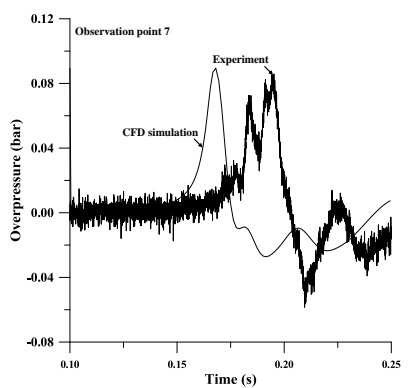

(a) Overpressure-time history

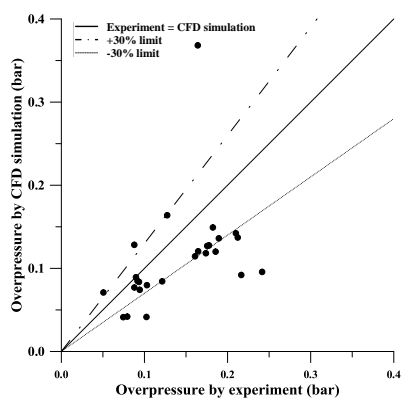

(b) Max. overpressures
Figure 5: Comparison of explosion loads between test and CFD simulation 
With the result of comparison, it seems that the validated modelling technique is appropriate. And it is applied further CFD simulations in the present study.

\subsection{VALILDATION OF FE MODELLING}

HSE (2003) performed a test of blast wall considering a blast pulse loading. The test by HSE (2003) is adopted to compare a result of NLFEA for the validation.

The target structure is a blast wall on offshore platform as shown in Figure 6. It consists of corrugated panels and support members to connect decks.

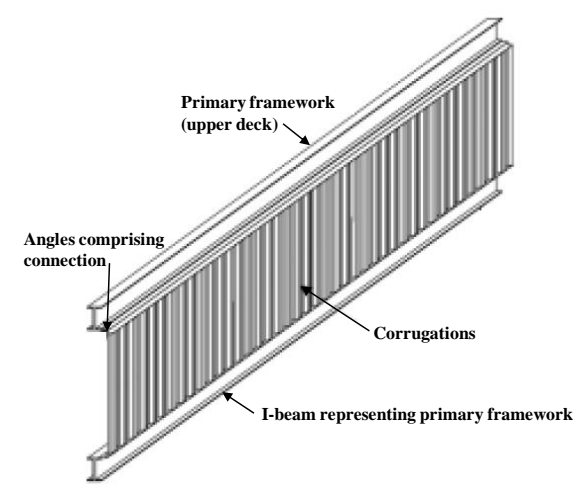

Figure 6: Target structure for validation of FE analysis (HSE, 2003)

Figure 7 descries the structural response under the blast pulse load by experimental test and NLFEA. The comparison shows that the FE modelling techniques developed in this study is proper to perform a structural analysis considering explosion loads.

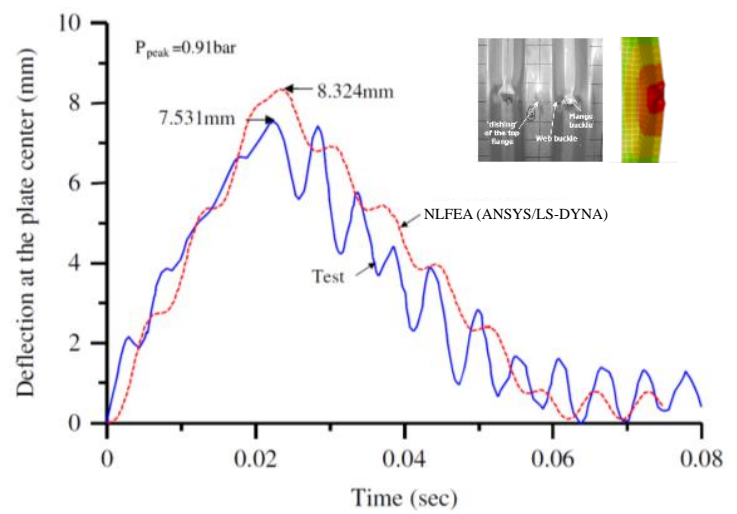

Figure 7: Comparison of structural response between test and NLFEA under the blast pulse load

\section{AN APPLIED EXAMPLE TO TOPSIDE STRUCTURE OF A FPSO}

A hypothetical FLNG vessel topside module is selected as a target structure for the applied examples including definition of explosion load, structural analysis and structural assessment.

Figures 8 and 9 present the layout of very large crude oil carrier class FLNG, and the layout and principal dimensions of the target structure. It is composed of three decks (process, mezzanine and upper decks), blast wall and process units (vessel and pipes).

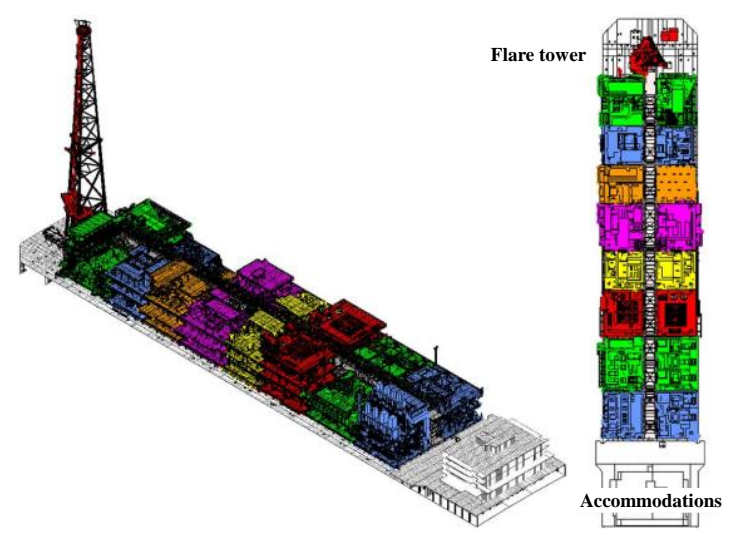

Figure 8: Layout of the FLNG installation

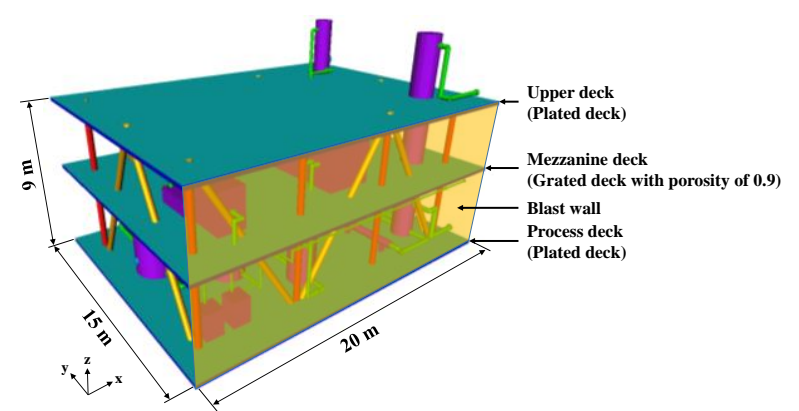

Figure 9: Layout and principal dimensions of the target structure

\subsection{ASSESSMENT OF EXPLOSION LOADS}

4.1 (a) Selection of Gas Dispersion Scenarios and Simulations

When defining explosion loads using the prescriptive or qualitative approaches, gas dispersion simulation is not mandatory. In contrast, gas dispersion simulations with dispersion scenarios must be conducted before the selection of explosion scenarios and analysis in the probabilistic assessment for obtaining the explosion loads.

When selecting gas dispersion scenarios, all possible parameters that can have an effect on the gas dispersion associated with the operating conditions should be considered. Gas dispersions can also be affected by environmental conditions, notably wind direction and speed (Paik and Czujko, 2010).

In this study, the method of selecting gas dispersion scenarios proposed by Paik and Czujko (2010) is used with seven parameters: wind direction, wind speed, leak rate, leak direction and leak position in the $\mathrm{X}, \mathrm{Y}$ and $\mathrm{Z}$ 
directions. Fifty gas dispersion scenarios selected by the probabilistic approach and sampling technique are shown in Table A.1.

For both dispersion and explosion simulations, the FLACS developed by GexCon AS is used. The FLACS code is a three-dimensional transient finite-volume CFD program used to simulate gas dispersion and explosion events (FLACS, 2014).

Figure 10 shows the target module and extent of analysis for dispersion. A ground area at the bottom of the structure also needs to be modelled to reflect the ground effect. The extent of the analysis is much wider than the structure size of $20 \times 15 \times 9(\mathrm{~m})$, thus taking into account the effects of turbulence associated with environmental conditions such as wind speed and direction.

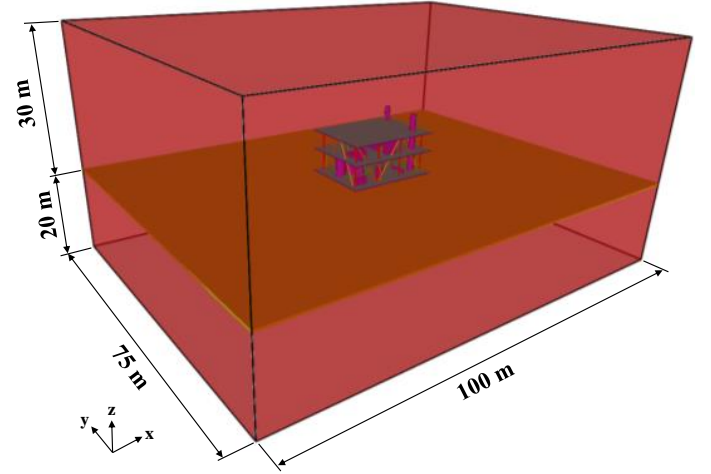

Figure 10: Target structure and extent of analysis for dispersion simulations

A gas composition of LNG, which is processed in FLNG operation is applied. Table 1 shows the gas composition of LNG.

Table 1: Gas composition of LNG

\begin{tabular}{|c|c|}
\hline Component & Mole fraction (\%) \\
\hline \hline Methane & 88.1 \\
\hline Ethane & 5.0 \\
\hline Propane & 4.9 \\
\hline Butane & 1.8 \\
\hline Pentane & 0.1 \\
\hline Nitrogen & 0.1 \\
\hline Total & 100 \\
\hline
\end{tabular}

In the case of gas dispersion, it is recommended that the grid size around the leak be used, as per Eq. (1) (FLACS, 2014).

$$
A_{C V}<2 A_{\text {leak }}
$$

where $A_{C V}=$ the minimum area around the leak position, and $A_{\text {leak }}=$ the area of the leak.

Figure 11 presents examples of applied dispersion grids in association with leak direction.

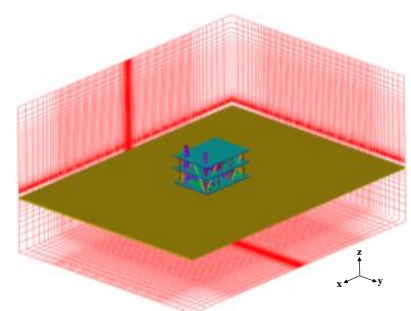

(a) Scenario 1

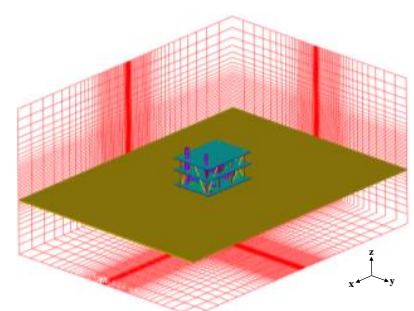

(b) Scenario 3
Figure 11: Examples of applied dispersion grids

Figure 12 illustrates the relationship between the maximum flammable and equivalent gas cloud volumes, which are the results of gas dispersion simulations. The flammable gas cloud signifies the actual gas cloud in the range of combustion, which is between the lower flammable limit and upper flammable limit. The equivalent gas cloud is the idealized gas cloud that has an equivalent ratio equal to 1 .

The equivalent gas cloud is generally proportional to the size of the flammable gas cloud. They also have a relationship with the function of the flammable or equivalent gas cloud. In this study, the sizes of equivalent gas cloud are almost half of the flammable gas cloud volumes.

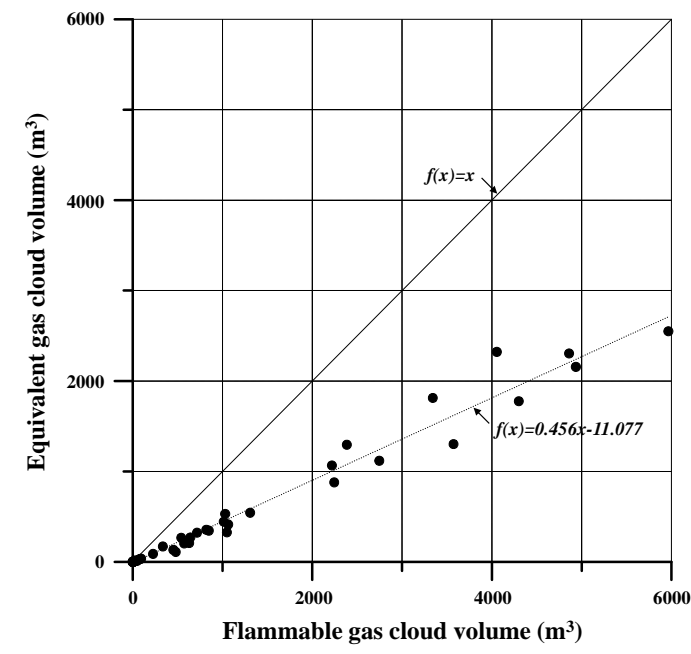

Figure 12: Relationship between the maximum flammable and equivalent gas clouds

The size of the equivalent gas cloud and the centre of the flammable gas cloud are used as the variables for selecting gas explosion scenarios.

4.1 (b) Selection of Gas Explosion Scenarios and
Simulations

When selecting gas explosion scenarios, all possible parameters that can have an effect on gas explosion should be considered, as in the selection of gas dispersion scenarios. Hydrocarbon explosions can be affected by dispersion-related parameters, which are size, location, concentration of gas clouds and ignition point. 
In this study, equivalent gas clouds are used, and four parameters, i.e. size of the gas cloud and the centre of the gas cloud in the $\mathrm{X}, \mathrm{Y}$ and $\mathrm{Z}$ directions, are considered in selecting the gas explosion scenarios. Fifty gas explosion scenarios selected using the method proposed by Paik and Czujko (2010) are shown in Table A.2.

Figure 13 shows the extent of analysis for explosion simulations in the FLACS. Although the area of analysis for the dispersion simulation is very wide, the explosion simulation requires a smaller area because there is no wind, and the blast wave allows the boundary effect to be ignored. The extent of analysis adopted to investigate the explosion loads is $80 \times 65 \times 40(\mathrm{~m})$.

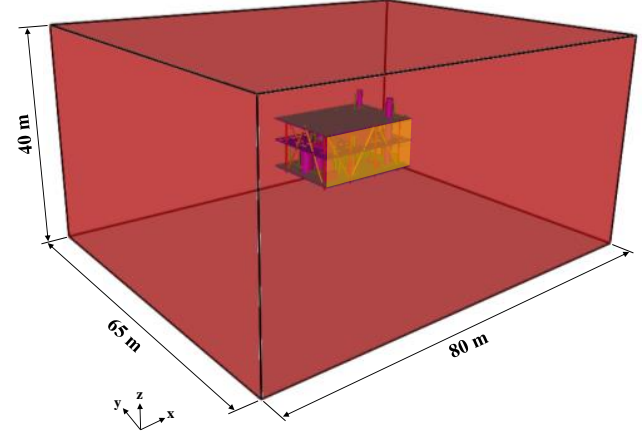

Figure 13: Target structure and extent of analysis for explosion simulations

For the gas explosion simulation, there is no need to generate fine grids around the leak area because the equivalent gas cloud is considered without gas release. The minimum grid size recommended for use is the value calculated by Eq. (2) (FLACS, 2014).

$$
\max . C V=0.1\left[V_{\text {gas }}^{1 / 3}\right]
$$

where $\max . C V=$ maximum size of the $\mathrm{CV}$ and $V_{g a s}=$ size of gas cloud volume.

To minimise the effect of the size of the CVs (grids), a distance between the grids of $0.5 \mathrm{~m}$ is used for all explosion scenarios. The total number of CVs is 565,192 . Figure 14 presents the applied grids for gas explosion simulations used in all explosion scenarios.

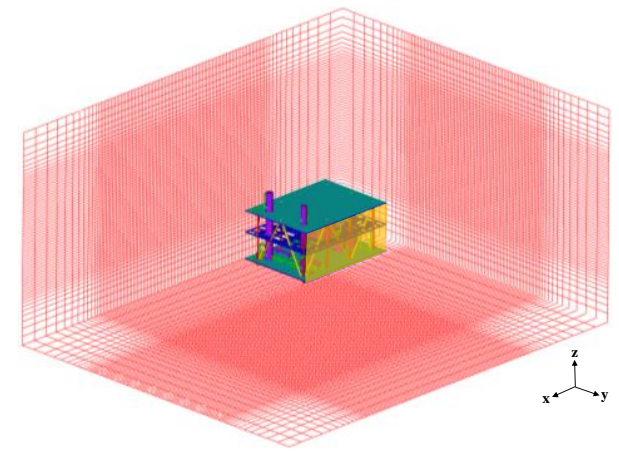

Figure 14: Applied grids and control volumes for explosion simulations
Figure 15 illustrates a representative result of gas explosion simulations, which is the effect of the equivalent gas cloud volume size on maximum overpressure in the entire monitoring region.

It shows that the size of the gas cloud volume can have a decisive effect on the explosion loads when the volume is less than $1000 \mathrm{~m}^{3}$. When the gas cloud is larger than $1000 \mathrm{~m}^{3}$, conditions of geometry such as congestion and confinement affect the explosion loads more than the size of gas cloud.

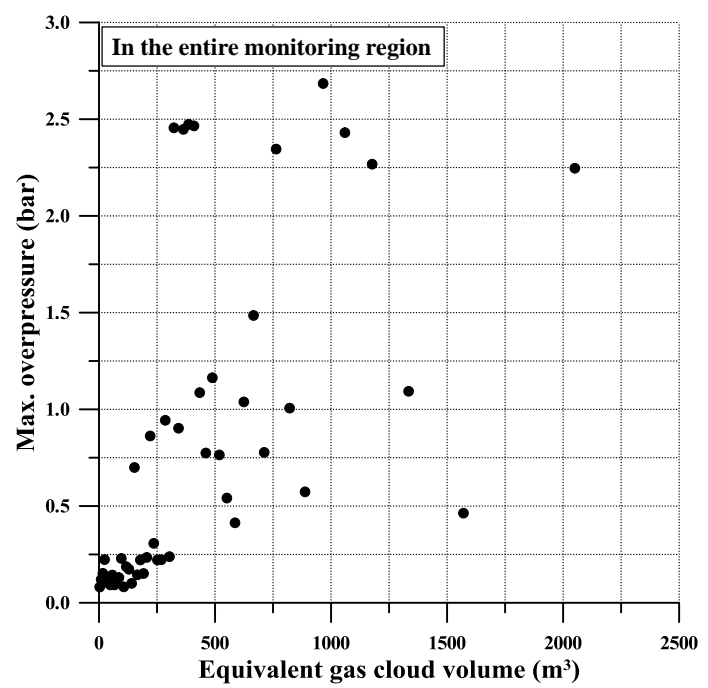

Figure 15: Effect of equivalent gas cloud volume on maximum overpressure

The explosion loads for each scenario obtained from CFD simulations are directly applied to the structural model for structural consequence analysis.

\subsection{CALCULATION OF GAS EXPLOSION FREQUENCY}

To generate the consequence exceedance curve and structural assessment proposed in the present study, the frequency of gas explosion scenarios should be calculated, which can be done with Eq. (3).

[Explosion fre.]=[Gas cloud fre.]X[Ignition prob.] (3)

\section{2 (a) Gas Cloud Frequency}

In the case of fire accidents, the leak frequency can be directly used. However, the gas cloud frequency in the case of an explosion must be recalculated from the release frequency because the explosion necessarily occurs after the release of the gas.

The detailed steps for the calculation of gas cloud frequency are as follows:

1) Categorisation of gas cloud volume. 
2) Summation of release frequency of gas dispersion scenarios depending on categories.

3) Calculation of the number of explosion scenarios included in each category.

4) Calculation of the gas cloud frequency of each scenario (total frequency/number of explosion scenarios in each category).

In this study, $25 \%$ probability is adopted to define the interval for categorisation. Table 2 shows the frequency of gas cloud explosion scenarios.

Table 2: Frequency of gas cloud explosion scenarios

\begin{tabular}{|c|c|c|c|}
\hline No. & $\begin{array}{c}\text { Gas cloud } \\
\text { frequency }(/ \mathrm{yr})\end{array}$ & No. & $\begin{array}{c}\text { Gas cloud } \\
\text { frequency }(/ \mathrm{yr})\end{array}$ \\
\hline 1 & $2.14 \mathrm{E}-3$ & 26 & $2.14 \mathrm{E}-3$ \\
\hline 2 & $7.45 \mathrm{E}-3$ & 27 & $2.92 \mathrm{E}-3$ \\
\hline 3 & $2.92 \mathrm{E}-3$ & 28 & $7.45 \mathrm{E}-3$ \\
\hline 4 & $2.92 \mathrm{E}-3$ & 29 & $2.14 \mathrm{E}-3$ \\
\hline 5 & $2.14 \mathrm{E}-3$ & 30 & $5.03 \mathrm{E}-3$ \\
\hline 6 & $2.92 \mathrm{E}-3$ & 31 & $5.03 \mathrm{E}-3$ \\
\hline 7 & $2.92 \mathrm{E}-3$ & 32 & $2.92 \mathrm{E}-3$ \\
\hline 8 & $7.45 \mathrm{E}-3$ & 33 & $7.45 \mathrm{E}-3$ \\
\hline 9 & $7.45 \mathrm{E}-3$ & 34 & $7.45 \mathrm{E}-3$ \\
\hline 10 & $2.92 \mathrm{E}-3$ & 35 & $2.92 \mathrm{E}-3$ \\
\hline 11 & $2.14 \mathrm{E}-3$ & 36 & $2.14 \mathrm{E}-3$ \\
\hline 12 & $5.03 \mathrm{E}-3$ & 37 & $5.03 \mathrm{E}-3$ \\
\hline 13 & $2.92 \mathrm{E}-3$ & 38 & $7.45 \mathrm{E}-3$ \\
\hline 14 & $2.92 \mathrm{E}-3$ & 39 & $5.03 \mathrm{E}-3$ \\
\hline 15 & $7.45 \mathrm{E}-3$ & 40 & $5.03 \mathrm{E}-3$ \\
\hline 16 & $5.03 \mathrm{E}-3$ & 41 & $2.92 \mathrm{E}-3$ \\
\hline 17 & $2.14 \mathrm{E}-3$ & 42 & $2.14 \mathrm{E}-3$ \\
\hline 18 & $2.92 \mathrm{E}-3$ & 43 & $2.14 \mathrm{E}-3$ \\
\hline 19 & $7.45 \mathrm{E}-3$ & 44 & $2.92 \mathrm{E}-3$ \\
\hline 20 & $7.45 \mathrm{E}-3$ & 45 & $2.14 \mathrm{E}-3$ \\
\hline 21 & $5.03 \mathrm{E}-3$ & 46 & $2.92 \mathrm{E}-3$ \\
\hline 22 & $7.45 \mathrm{E}-3$ & 47 & $7.45 \mathrm{E}-3$ \\
\hline 23 & $7.45 \mathrm{E}-3$ & 48 & $7.45 \mathrm{E}-3$ \\
\hline 24 & $5.03 \mathrm{E}-3$ & 49 & $7.45 \mathrm{E}-3$ \\
\hline 25 & $2.14 \mathrm{E}-3$ & 50 & $7.45 \mathrm{E}-3$ \\
\hline
\end{tabular}

\section{2 (b) Ignition Probability}

Cox et al. (1990), Oil and Gas UK (2006) and OGP (2010) suggest ignition models for the hydrocarbon events on offshore installations. The ignition probability suggested by OGP has largely referred to the Oil and Gas UK model (OGP, 2010).

The ignition probability is generally related to release type (gas, liquid, etc.), leak rate and type of offshore structure. In this study, the ignition probability of an offshore gas release event is considered. Figure 16 shows the ignition probabilities of gas release on offshore installations. Among the ignition models, the ignition probability proposed by OGP (2010) is applied in this study because it calculates the ignition probability in detail. The probability can be expressed by Eq. (4).

$$
\log \left(I P_{O G P}\right)= \begin{cases}0.1113 \cdot \log (x)-2.8857 & \text { for } 0.1 \leq x<1 \\ 1.2143 \cdot \log (x)-2.8865 & \text { for } 1 \leq x<50 \\ 0.15 & \text { for } 50 \leq x<1000\end{cases}
$$

where $I P_{O G P}=$ ignition probability suggested by OGP, and $x=$ leak rate.

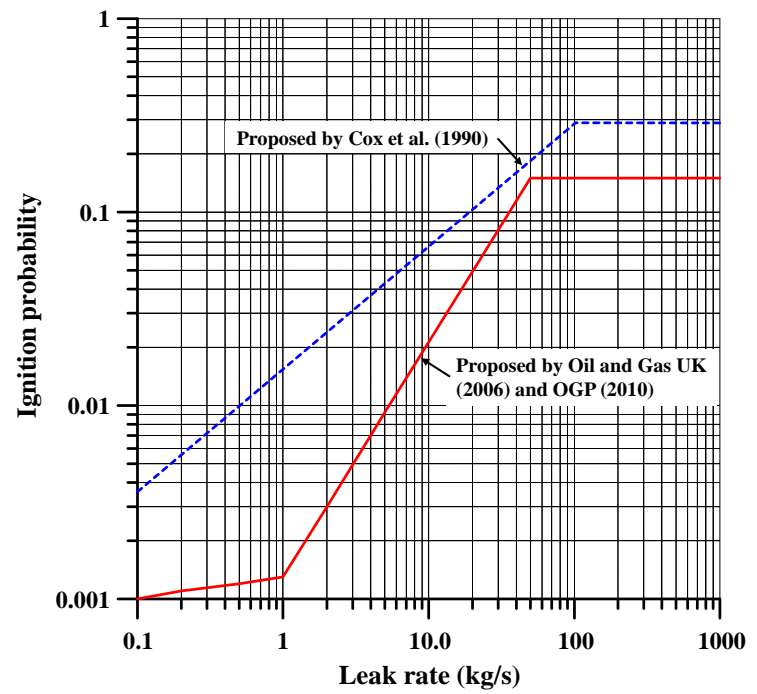

Figure 16: Ignition probabilities depending on the leak rate

Table 3: Ignition probability depending on the leak rate of gas dispersion scenarios

\begin{tabular}{|c|c||c|c|}
\hline No. & $\begin{array}{c}\text { Ignition } \\
\text { probability }\end{array}$ & No. & $\begin{array}{c}\text { Ignition } \\
\text { probability }\end{array}$ \\
\hline 1 & $1.46 \mathrm{E}-5$ & 26 & $1.46 \mathrm{E}-5$ \\
\hline 2 & $5.10 \mathrm{E}-5$ & 27 & $2.00 \mathrm{E}-5$ \\
\hline 3 & $2.00 \mathrm{E}-5$ & 28 & $5.10 \mathrm{E}-5$ \\
\hline 4 & $2.00 \mathrm{E}-5$ & 29 & $1.46 \mathrm{E}-5$ \\
\hline 5 & $1.46 \mathrm{E}-5$ & 30 & $3.44 \mathrm{E}-5$ \\
\hline 6 & $2.00 \mathrm{E}-5$ & 31 & $3.44 \mathrm{E}-5$ \\
\hline 7 & $2.00 \mathrm{E}-5$ & 32 & $2.00 \mathrm{E}-5$ \\
\hline 8 & $5.10 \mathrm{E}-5$ & 33 & $5.10 \mathrm{E}-5$ \\
\hline 9 & $5.10 \mathrm{E}-5$ & 34 & $5.10 \mathrm{E}-5$ \\
\hline 10 & $2.00 \mathrm{E}-5$ & 35 & $2.00 \mathrm{E}-5$ \\
\hline 11 & $1.46 \mathrm{E}-5$ & 36 & $1.46 \mathrm{E}-5$ \\
\hline 12 & $3.44 \mathrm{E}-5$ & 37 & $3.44 \mathrm{E}-5$ \\
\hline 13 & $2.00 \mathrm{E}-5$ & 38 & $5.10 \mathrm{E}-5$ \\
\hline 14 & $2.00 \mathrm{E}-5$ & 39 & $3.44 \mathrm{E}-5$ \\
\hline 15 & $5.10 \mathrm{E}-5$ & 40 & $3.44 \mathrm{E}-5$ \\
\hline 16 & $3.44 \mathrm{E}-5$ & 41 & $2.00 \mathrm{E}-5$ \\
\hline 17 & $1.46 \mathrm{E}-5$ & 42 & $1.46 \mathrm{E}-5$ \\
\hline 18 & $2.00 \mathrm{E}-5$ & 43 & $1.46 \mathrm{E}-5$ \\
\hline 19 & $5.10 \mathrm{E}-5$ & 44 & $2.00 \mathrm{E}-5$ \\
\hline 20 & $5.10 \mathrm{E}-5$ & 45 & $1.46 \mathrm{E}-5$ \\
\hline 21 & $3.44 \mathrm{E}-5$ & 46 & $2.00 \mathrm{E}-5$ \\
\hline 22 & $5.10 \mathrm{E}-5$ & 47 & $5.10 \mathrm{E}-5$ \\
\hline 23 & $5.10 \mathrm{E}-5$ & 48 & $5.10 \mathrm{E}-5$ \\
\hline 24 & $3.44 \mathrm{E}-5$ & 49 & $5.10 \mathrm{E}-5$ \\
\hline 25 & $1.46 \mathrm{E}-5$ & 50 & $5.10 \mathrm{E}-5$ \\
\hline & & & \\
\hline
\end{tabular}


Table 3 shows the ignition probability for each of the gas dispersion scenarios. The ignition probability of gas dispersion scenarios cannot be directly used in the gas explosion scenarios because the latter are re-selected with the results of gas dispersion simulations. Thus, the total ignition probability of gas dispersions divided by 50 (6.84E-3 for each scenario) is equally used for the gas explosion scenarios.

\section{2 (c) Gas Explosion Frequency}

Given the gas cloud frequency and ignition probability, the gas explosion frequency can be calculated. Table 4 shows the gas explosion frequency for each gas explosion scenario.

Table 4: Gas explosion frequency of explosion scenarios

\begin{tabular}{|c|c||c|c|}
\hline No. & $\begin{array}{c}\text { Gas explosion } \\
\text { frequency (/yr) }\end{array}$ & No. & $\begin{array}{c}\text { Gas explosion } \\
\text { frequency }(/ \mathrm{yr})\end{array}$ \\
\hline 1 & $1.46 \mathrm{E}-5$ & 26 & $1.46 \mathrm{E}-5$ \\
\hline 2 & $5.10 \mathrm{E}-5$ & 27 & $2.00 \mathrm{E}-5$ \\
\hline 3 & $2.00 \mathrm{E}-5$ & 28 & $5.10 \mathrm{E}-5$ \\
\hline 4 & $2.00 \mathrm{E}-5$ & 29 & $1.46 \mathrm{E}-5$ \\
\hline 5 & $1.46 \mathrm{E}-5$ & 30 & $3.44 \mathrm{E}-5$ \\
\hline 6 & $2.00 \mathrm{E}-5$ & 31 & $3.44 \mathrm{E}-5$ \\
\hline 7 & $2.00 \mathrm{E}-5$ & 32 & $2.00 \mathrm{E}-5$ \\
\hline 8 & $5.10 \mathrm{E}-5$ & 33 & $5.10 \mathrm{E}-5$ \\
\hline 9 & $5.10 \mathrm{E}-5$ & 34 & $5.10 \mathrm{E}-5$ \\
\hline 10 & $2.00 \mathrm{E}-5$ & 35 & $2.00 \mathrm{E}-5$ \\
\hline 11 & $1.46 \mathrm{E}-5$ & 36 & $1.46 \mathrm{E}-5$ \\
\hline 12 & $3.44 \mathrm{E}-5$ & 37 & $3.44 \mathrm{E}-5$ \\
\hline 13 & $2.00 \mathrm{E}-5$ & 38 & $5.10 \mathrm{E}-5$ \\
\hline 14 & $2.00 \mathrm{E}-5$ & 39 & $3.44 \mathrm{E}-5$ \\
\hline 15 & $5.10 \mathrm{E}-5$ & 40 & $3.44 \mathrm{E}-5$ \\
\hline 16 & $3.44 \mathrm{E}-5$ & 41 & $2.00 \mathrm{E}-5$ \\
\hline 17 & $1.46 \mathrm{E}-5$ & 42 & $1.46 \mathrm{E}-5$ \\
\hline 18 & $2.00 \mathrm{E}-5$ & 43 & $1.46 \mathrm{E}-5$ \\
\hline 19 & $5.10 \mathrm{E}-5$ & 44 & $2.00 \mathrm{E}-5$ \\
\hline 20 & $5.10 \mathrm{E}-5$ & 45 & $1.46 \mathrm{E}-5$ \\
\hline 21 & $3.44 \mathrm{E}-5$ & 46 & $2.00 \mathrm{E}-5$ \\
\hline 22 & $5.10 \mathrm{E}-5$ & 47 & $5.10 \mathrm{E}-5$ \\
\hline 23 & $5.10 \mathrm{E}-5$ & 48 & $5.10 \mathrm{E}-5$ \\
\hline 24 & $3.44 \mathrm{E}-5$ & 49 & $5.10 \mathrm{E}-5$ \\
\hline 25 & $1.46 \mathrm{E}-5$ & 50 & $5.10 \mathrm{E}-5$ \\
\hline & & & \\
\hline
\end{tabular}

\subsection{NONLINEAR STRUCTURAL CONSEQUENCE ANALYSIS}

\section{3 (a) Finite Element Modelling}

\section{Numerical model}

The target structure for finite element analysis is the same as that in the model for dispersion and explosion simulations. The entire module is used for the extent of analysis as shown in Figure 17.

The finite element model is generated using the ANSYS/LS-DYNA with shell elements (Shell 163) for the entire structure including the plates, blast wall, beams and columns. Shell 163 element in ANSYS/LS-DYNA is a 4-node element with both bending and membrane capabilities, and both in-plane and normal loads are permitted (ANSYS/LS-DYNA, 2014). Thus, it is proper for use in structural analysis under dynamic loads.

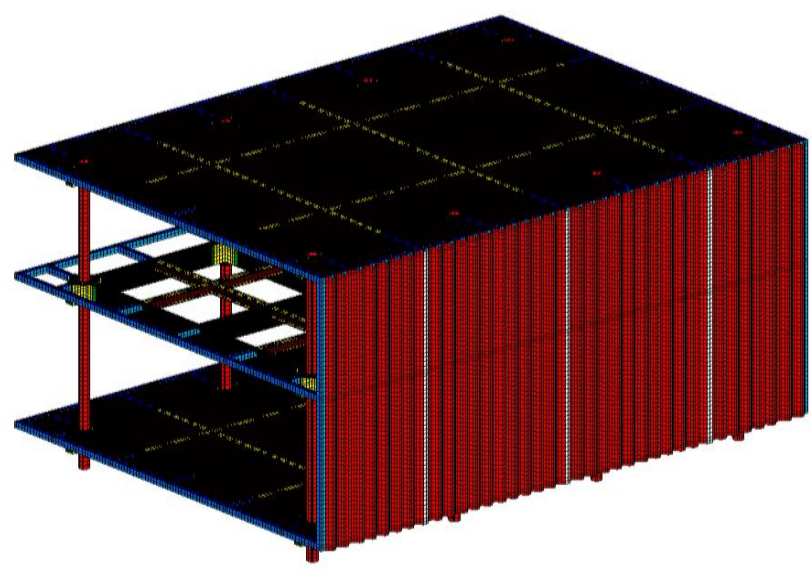

Figure 17: Finite element model of the target structure

\section{$\underline{\text { Material modelling }}$}

All of the members involved in the present study are made of mild steel. Table 5 shows the material properties of mild steel under static load.

Table 5: Material properties of mild steel under static load

\begin{tabular}{|c|c|c|}
\hline \multicolumn{2}{|l|}{ Density $\left(\rho, \mathrm{kg} / \mathrm{m}^{3}\right)$} & 7,890 \\
\hline \multicolumn{2}{|c|}{ Elastic modulus (E, MPa) } & 205,800 \\
\hline \multicolumn{2}{|l|}{ Yield stress $\left(\sigma_{\mathrm{Y}}, \mathrm{MPa}\right)$} & 235 \\
\hline \multicolumn{2}{|l|}{ Poisson's ratio $(v)$} & 0.3 \\
\hline \multicolumn{2}{|l|}{ Fracture strain $\left(\varepsilon_{\mathrm{f}}\right)$} & 0.3 \\
\hline \multirow{2}{*}{ Cowper-Symonds coefficients } & $\mathrm{C}(1 / \mathrm{s})$ & 40.4 \\
\hline & $\mathrm{q}$ & 5 \\
\hline
\end{tabular}

When a dynamic load is applied in the form of an explosion load, the strain rate effect, which is a dynamic effect, should be considered. There are various methods for considering the dynamic effect of the material. The standard methods apply the DLF (Biggs, 1964), SDOF (Biggs, 1964; Paik, 2011), or Cowper-Symonds equations (Cowper and Symonds, 1957).

The DLF is generally used to amplify the structural response under static load. SDOF is a simple method for calculating the response of a simplified structure as a spring. These two methods are efficient and convenient, but they yield only approximate results and are not suitable for complex structures such as the target structure in this study

Therefore, Cowper-Symonds equations are used to obtain a more accurate structural response. The equations are expressed as in Eq. (5), depending on the strain (Cowper and Symonds, 1957). They can be applied to the elastic, perfectly plastic material model applied in this study. 


$$
\begin{aligned}
& \sigma_{Y d}=\sigma_{Y}\left[1+\left(\frac{\dot{\varepsilon}}{C}\right)\right]^{1 / q} \\
& \varepsilon_{f d}=\varepsilon_{f}\left[1+\left(\frac{\dot{\varepsilon}}{C}\right)\right]^{-1 / q}
\end{aligned}
$$

where $\sigma_{Y}$ and $\sigma_{Y d}=$ static and dynamic yield stresses, $\dot{\varepsilon}=$ strain rate, $C$ and $q=$ Cowper-Symonds coefficients and, $\varepsilon_{f}$ and $\varepsilon_{f d}=$ static and dynamic fracture strains.

\section{$\underline{\text { Boundary conditions }}$}

In general, the topside structures on offshore installations are fixed at support members on the deck of the hull side. However, there is no rotational restriction.

Among the six degrees of freedom in NLFEM, a fixed condition with three displacements is applied at the bottom of the main columns. Figure 18 shows the boundary conditions adopted in the present study.

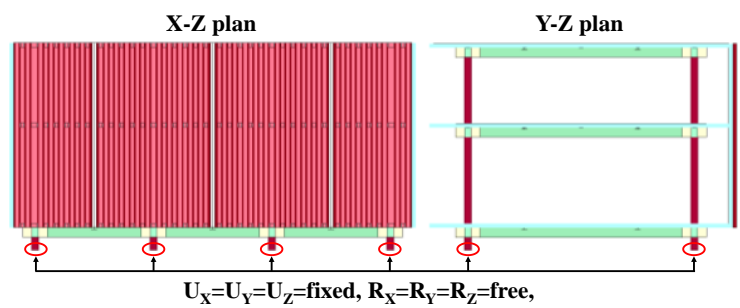

Figure 18: Applied boundary conditions

\section{$\underline{\text { Loading conditions }}$}

Paik et al. (2014) suggested that the actual explosion loads be applied by CFD or experimentation because the structural behaviour is quite different according to the usage of idealised (uniformly distributed) and actual (non-uniformly distributed) explosion loads. The procedure applies the actual explosion loads transferred by the interface program between the CFD and finite element analysis for structural analysis subjected to actual explosion loads.

In this study, the FLACS2DYNA (2013) interface program is adopted to transfer the actual explosion loads obtained from FLACS CFD simulations to the ANSYS/LS-DYNA NLFEM. FLACS2DYNA transfers the explosion loads taking into account the CV system in CFD and the elements in NLFEM.

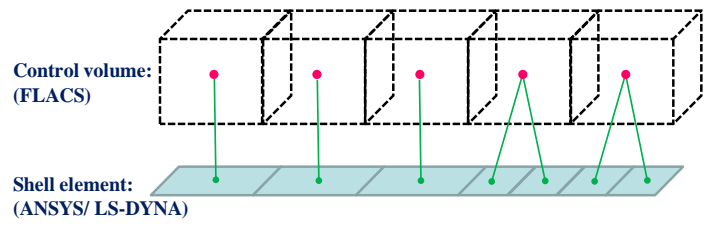

Figure 19: Concept of the FLACS2DYNA interface program (FLACS2DYNA, 2013)

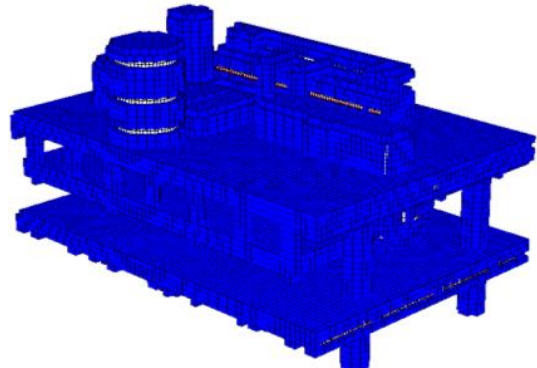

Figure 20: Mapping view of explosion loads between CVs in CFD and elements in FEM

Figures 19 and 20 illustrate the concept of the FLACS2DYNA interface program and the mapping view of explosion loads between CVs in FLACS and elements in ANSYS/LS-DYNA (FLACS2DYNA, 2013).

\section{Mesh sensitivity study}

For effectiveness and accuracy, a part of the deck is used for the mesh sensitivity study on deflection, and a part of the blast wall is applied for plastic strain as shown in Figure 21 .

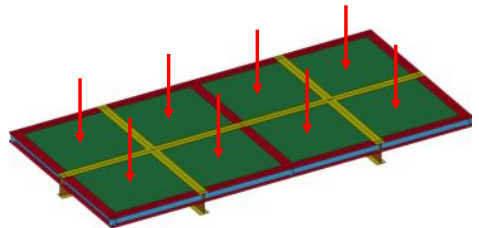

(a) Part of deck

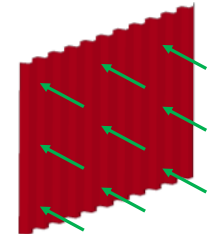

(b) Part of blast wall
Figure 21: Extent of analysis and loading directions for the mesh sensitivity study

Figure 22 presents the results of the mesh sensitivity study. From the results, an element of 150 x 150 (mm) is selected as the proper mesh size in terms of time and accuracy.

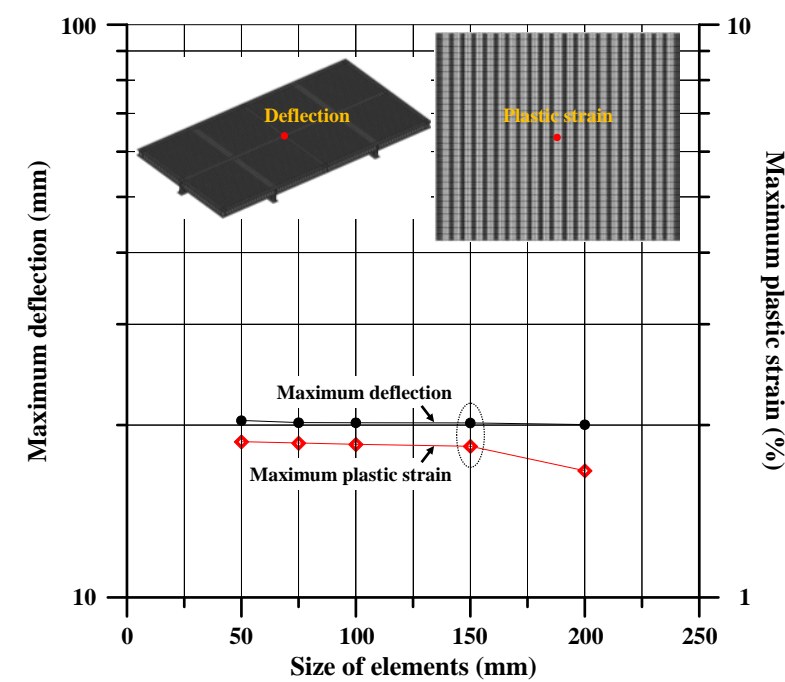

Figure 22: Results of the mesh sensitivity study 


\section{Obtaining the structural response}

Deflection and plastic strain are investigated as the elements of structural response. The deflections are observed at the centre of the plate members, which are the blast wall and the upper and process decks, and the strains are obtained at structural members such as the main frame, secondary frames, column and blast wall. Figure 23 depicts the monitoring points and elements used to obtain the structural response, and Table 6 lists the location of each monitoring element.
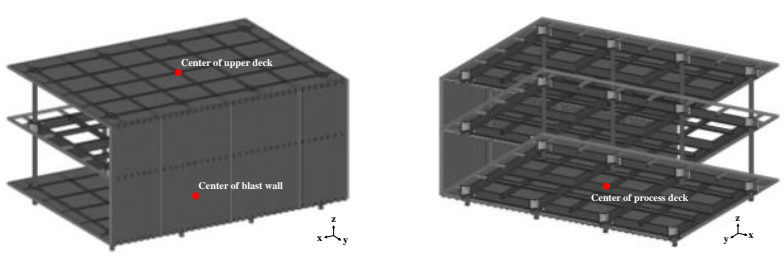

(a) Monitoring points for obtaining deflection
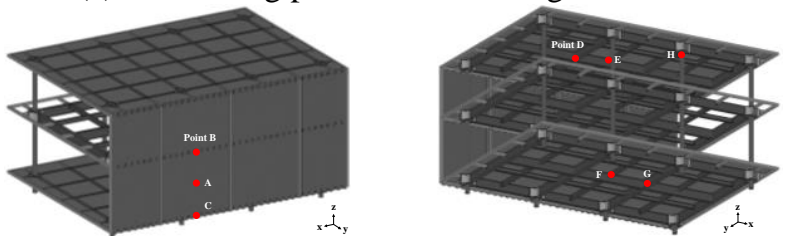

(b) Monitoring elements for obtaining plastic strain

Figure 23: Obtaining the structural response

Table 6: Location of monitoring elements

\begin{tabular}{|c|c|c|}
\hline Point no. & Location & Note \\
\hline $\mathrm{A}$ & Centre & \multirow{3}{*}{$\begin{array}{l}\text { Blast } \\
\text { wall }\end{array}$} \\
\hline $\mathrm{B}$ & Connection (mezzanine deck) & \\
\hline $\mathrm{C}$ & Connection (process deck) & \\
\hline $\mathrm{D}$ & Main frame & \multirow{2}{*}{$\begin{array}{c}\text { Upper } \\
\text { deck }\end{array}$} \\
\hline $\mathrm{E}$ & Secondary frame & \\
\hline $\mathrm{F}$ & Main frame & \multirow{2}{*}{$\begin{array}{c}\text { Process } \\
\text { deck }\end{array}$} \\
\hline $\mathrm{G}$ & Secondary frame & \\
\hline $\mathrm{H}$ & Column at upper deck & - \\
\hline
\end{tabular}

4.3 (b) Nonlinear Structural Response of the Topside Structure

Figures 24 and 25 illustrate the results of structural analysis, which are maximum deflection at the blast wall and decks, and plastic strain at the blast wall, frames and column.

In Figure 24, deflections at process deck are larger than responses at blast wall and process decks due to the direction of self-weight and equipment.

As shown in Figure 25(a), the plastic strain at the connection between the blast wall and the process deck is bigger on the blast wall because the target structure in this study does not have a support member between the blast wall and the decks. This indicates that the support member is needed for structural safety of the connection. The response of the main and secondary frames on the process and upper decks, as shown in Figures 25(b) and (c), signify that the explosion has a more serious effect on the main frames.

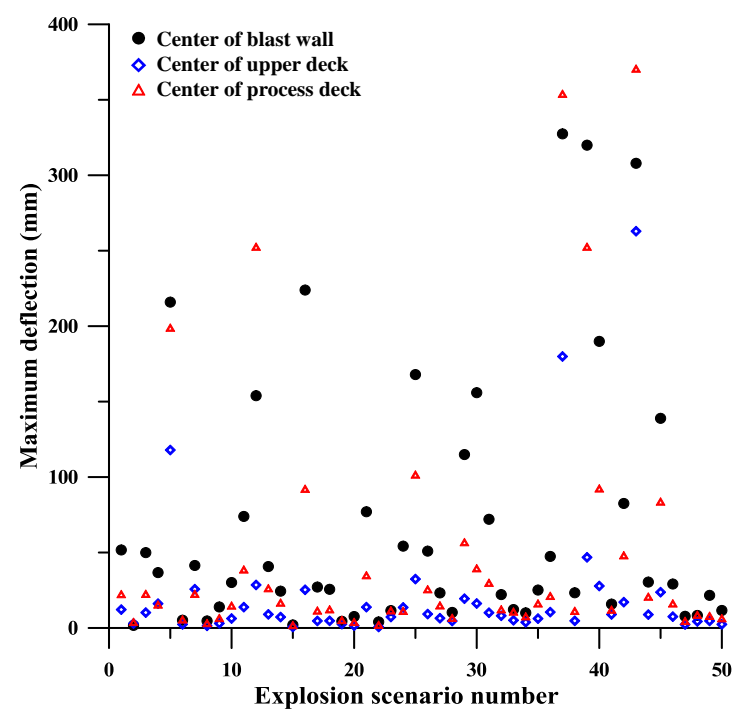

Figure 24: Maximum deflection at the centre of the blast wall and decks

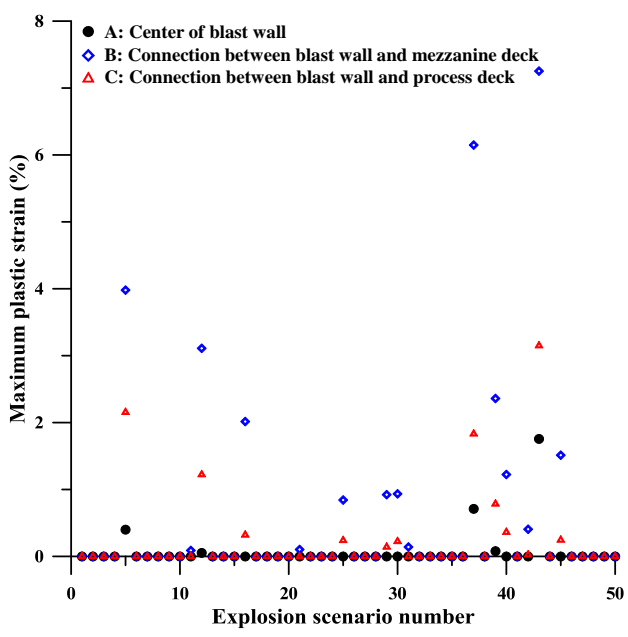

(a) On blast wall

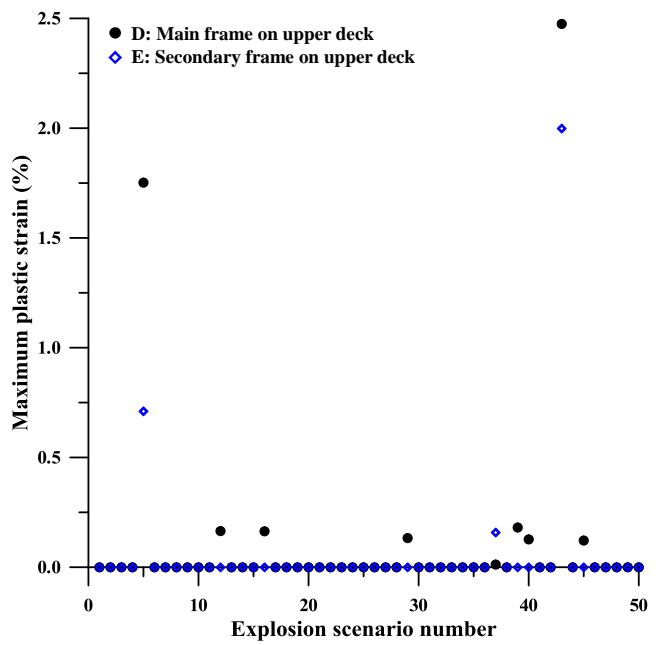

(b) On upper deck 


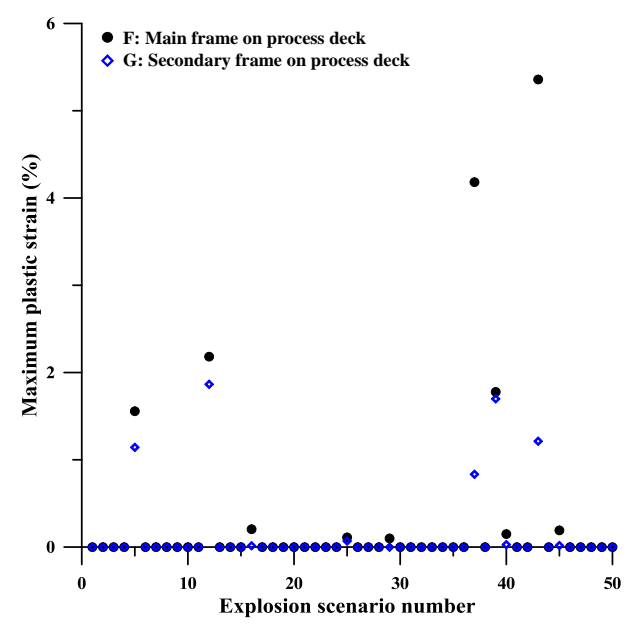

(c) On process deck

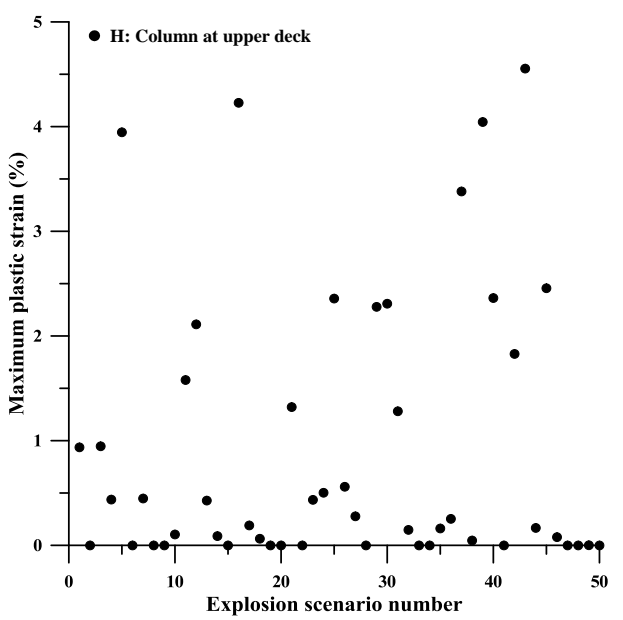

(d) At column

Figure 25: Maximum plastic strain at blast wall, frames and column

Figure 26 gives an example of total displacement distributions in a representative explosion scenario (scenario 10) at different times. It shows that an additional torsional behaviour occurs as a result of nonuniformly distributed actual explosion loads.

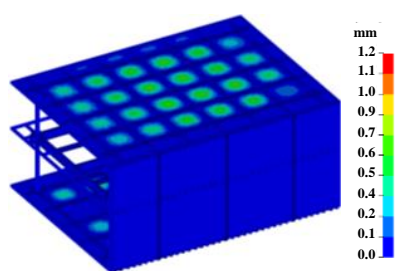

(a) $0.1 \mathrm{~s}$ after ignition

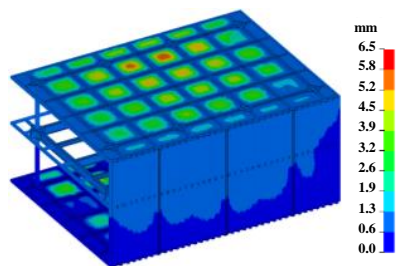

(c) $0.5 \mathrm{~s}$ after ignition

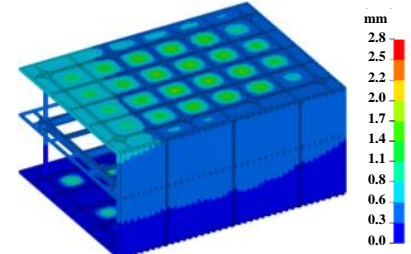

(b) $0.3 \mathrm{~s}$ after ignition

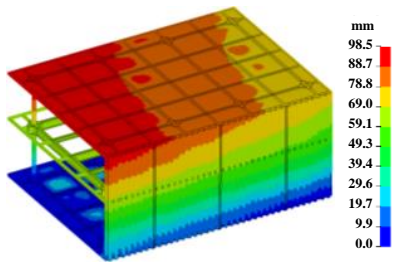

(d) $0.7 \mathrm{~s}$ after ignition

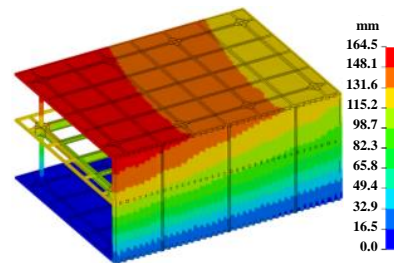

(e) $0.9 \mathrm{~s}$ after ignition

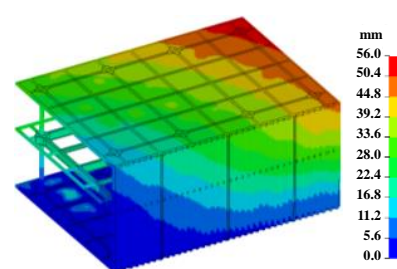

(f) $1.1 \mathrm{~s}$ after ignition
Figure 26: Example of total displacement distribution in explosion scenario 10

Detailed maximum deflections and plastic strains subjected to actual explosion load sets of 50 explosion scenarios are presented in Tables A.3 and A.4.

\section{$4.4 \quad$ STRUCTURAL ASSESSMENT \\ 4.4 (a) Consequence Exceedance Curve}

Czujko and Paik (2015) suggested a new method for the accidental limit design of structures subjected to hydrocarbon explosions, in which the explosion loads and structural consequence are combined with the consequence probability of exceedance. The procedure adopts a new method as named 'consequence exceedance curve' based on the method proposed by Czujko and Paik (2015) for structural assessment.

Using the results of 50 nonlinear structural analyses, the consequence exceedance curves are generated. The approach to obtaining these curves is similar to that for the explosion load exceedance curve proposed by Paik and Czujko (2010). Structural responses such as deflection or strain can be used instead of explosion loads, which are overpressure, drag force and impulse.

Figure 27 shows the maximum structural consequence exceedance curves at the blast wall, decks, frames and column. Figure 27(a) presents the maximum deflection exceedance curves, and Figures 27(b)-(e) illustrate the maximum plastic strain exceedance curves at the structural members.

The consequence exceedance curves are for investigating the structural response at risk acceptance level. With the curves, designers can now more accurately predict the structural response directly relating to the actual loads of all explosion scenarios.

\section{4 (b) Structural Consequence at Risk Acceptance Level}

Plastic strain is the parameter generally used for structural assessment in explosions, and it is applied to define the structural consequence at the acceptance level.

A risk level of $10^{-4} / \mathrm{yr}$ is adopted as acceptable in this study, and Table 7 shows the plastic strain at risk acceptance level in the consequence exceedance curves shown in Figures 27(b)-(e). 
Table 7: Plastic strain at a risk acceptance level of $10^{-4} / \mathrm{yr}$ in consequence exceedance curves (in \%)

\begin{tabular}{|c|c|c|}
\hline \multicolumn{2}{|r|}{ Location } & $\begin{array}{c}\text { Plastic strain at risk } \\
\text { acceptance level }\end{array}$ \\
\hline \multirow{3}{*}{$\begin{array}{l}\text { Blast } \\
\text { wall }\end{array}$} & Centre & 0.41 \\
\hline & $\begin{array}{l}\text { Connection } \\
\text { (mezzanine deck) }\end{array}$ & 2.24 \\
\hline & $\begin{array}{l}\text { Connection } \\
\text { (process deck) }\end{array}$ & 0.64 \\
\hline \multirow{2}{*}{$\begin{array}{c}\text { Upper } \\
\text { deck }\end{array}$} & Main frame & 0.15 \\
\hline & Secondary frame & 0.00 \\
\hline \multirow{2}{*}{$\begin{array}{c}\text { Process } \\
\text { deck }\end{array}$} & Main frame & 1.66 \\
\hline & Secondary frame & 0.57 \\
\hline \multicolumn{2}{|c|}{ Column at upper deck } & 3.97 \\
\hline
\end{tabular}

4.4 (c) Structural Assessment of the Topside Structure

Acceptance criteria are needed for the structural assessment of the topside structure. These criteria are normally determined according to a functional requirement (Czujko and Paik, 2015). Czujko and Paik (2015) suggested the criteria of $1 \%, 5 \%$ and $10 \%$ of the plastic strain limit for the structural assessment of the topside structure.

In this study, $1 \%$ and $5 \%$ of plastic strain limits are adopted for the structural assessment. Additionally, 3\% of strain is applied.

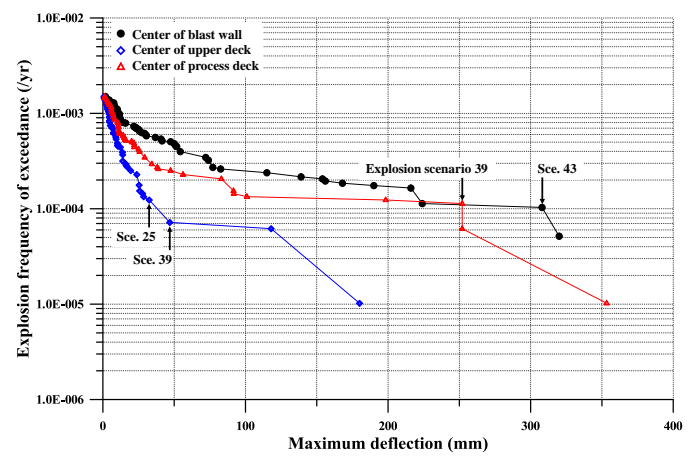

(a) Maximum deflection at blast wall and decks

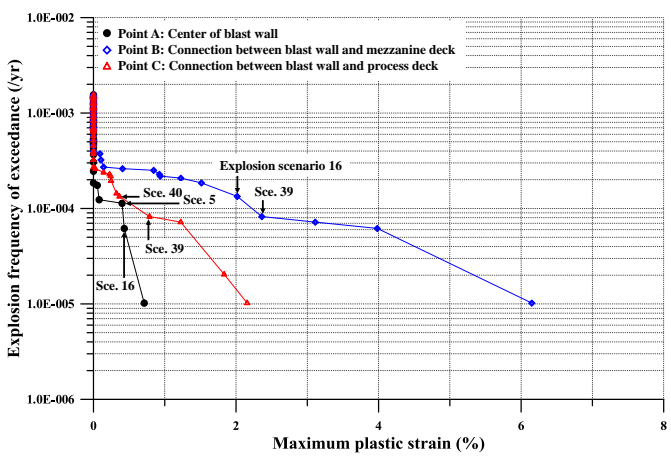

(b) Maximum plastic strain at blast wall

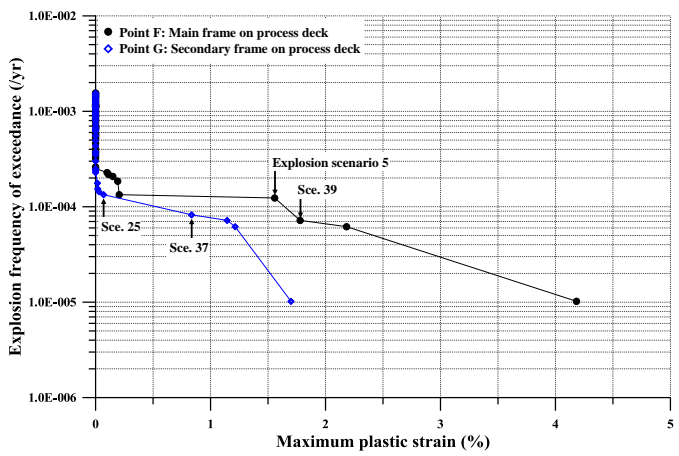

(d) Maximum plastic strain at process deck

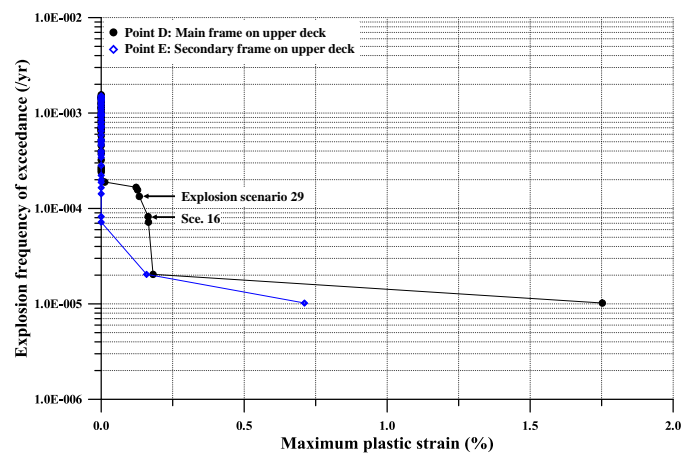

(c) Maximum plastic strain at upper deck

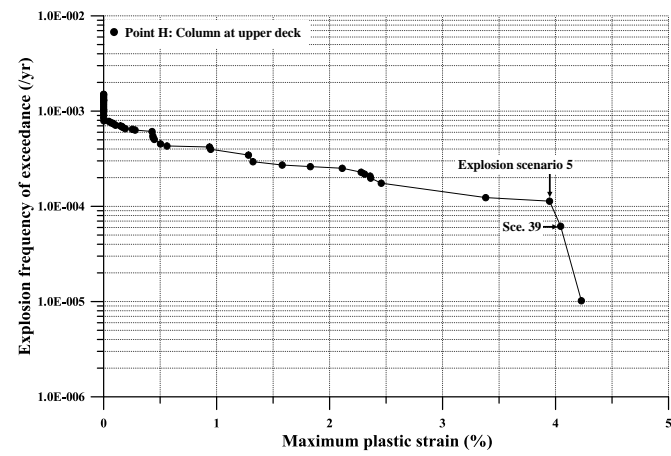

(e) Maximum plastic strain at column

Figure 27: Probability exceedance of explosion frequency versus maximum structural consequence 
Table 8: Structural assessment of topside structure with risk acceptance level

\begin{tabular}{|c|l|c|c|c|}
\hline \multicolumn{2}{|c|}{ Location } & \multicolumn{3}{c|}{ Plastic strain } \\
\cline { 3 - 5 } & Centre & $1 \%$ & $3 \%$ & $5 \%$ \\
\cline { 2 - 5 } $\begin{array}{c}\text { Blast } \\
\text { wall }\end{array}$ & $\begin{array}{l}\text { Connection } \\
(\text { mezzanine deck) }\end{array}$ & $\underline{\mathrm{NA}}$ & $\mathrm{A}$ & $\mathrm{A}$ \\
\cline { 2 - 5 } & $\begin{array}{l}\text { Connection } \\
\text { (process deck) }\end{array}$ & $\mathrm{A}$ & $\mathrm{A}$ & $\mathrm{A}$ \\
\hline \multirow{2}{*}{$\begin{array}{c}\text { Upper } \\
\text { deck }\end{array}$} & Main frame & $\mathrm{A}$ & $\mathrm{A}$ & $\mathrm{A}$ \\
\cline { 2 - 5 } & Secondary frame & $\mathrm{A}$ & $\mathrm{A}$ & $\mathrm{A}$ \\
\hline $\begin{array}{c}\text { Process } \\
\text { deck }\end{array}$ & Main frame & $\mathrm{NA}$ & $\mathrm{A}$ & $\mathrm{A}$ \\
\cline { 2 - 5 } & Secondary frame & $\mathrm{A}$ & $\mathrm{A}$ & $\mathrm{A}$ \\
\hline \multicolumn{2}{|c|}{ Column at upper deck } & $\underline{\mathrm{NA}}$ & $\underline{\mathrm{NA}}$ & $\mathrm{A}$ \\
\hline
\end{tabular}

Note: A signifies acceptable, and NA signifies not acceptable.

Table 8 shows whether the structural response satisfies the criteria. Some structures subjected to actual loads do not satisfy the $1 \%$ of plastic strain limit. With Table 8 , the structural safety can be accurately evaluated because the consequence exceedance curves consider the actual (non-idealized and non-uniform) explosion loads.

\section{CONCLUSIONS}

The objectives of this study were to develop an advanced procedure for the quantitative risk assessment of offshore installations in hydrocarbon explosions by applying an entirely probabilistic approach and to demonstrate the procedure with an applied example.

The procedure selects gas dispersion and explosion scenarios based on the probabilistic method, and CFD and/or experimental tests are used to simulate dispersion and explosions.

For the structural consequence analysis, this procedure directly applies actual explosion loads to a structural model using the interface program between CFD and NLFEM. In addition, the consequence exceedance curve based on the structural response under actual explosion loads and explosion frequency is suggested for the structural assessment of topside structures.

The following conclusions and insights can be drawn from the results of this study:

- $\quad$ The advanced procedure proposed here is practicable by using a fully probabilistic approach for explosion risk assessment of offshore installations.

- It can produce a realistic structural response using the actual explosion loads and shell element in the finite element model.

- The procedure adopts a method for structural assessment using consequence exceedance curves, which consider sets of actual explosion loads of all explosion scenarios.
- The procedure can be easily applied to any structure against explosion events and can reduce the uncertainties inherent in the assessment of explosion loads and structures.

\section{ACKNOWLEDGEMENTS}

This study was financially supported by the 2016 PostDoctoral Development Program of Pusan National University.

\section{REFERENCES}

1. ABS (2013) Accidental load analysis and design for offshore structures. American Bureau of Shipping, TX, USA.

2. ANSYS/LS-DYNA (2014) User's manual for ANSYS/LS-DYNA version 14.5. ANSYS Inc., Canonsburg, PA, USA.

3. API (2006) Design of offshore facilities against fire and blast loading. API-RP2FB. American Petroleum Institute, Washington, DC, USA.

4. BIGGS, J.M. (1964) Introduction of structural dynamics. McGraw-Hill, New York.

5. COWPER, G. and SYMONDS, P.S. (1957) Strain-hardening and strain-rate effects in the impact loading of cantilever beans. Technical report 28. Department of Applied Mathematics, Brown University, Providence, RI, USA.

6. COX, A.W., LEES, F.P. and ANG, M.L. (1990) Classification of hazardous locations. Institution of Chemical Engineers, Warwickshire, UK.

7. CZUJKO, J. (2001) Design of offshore facilities to resist gas explosion hazard: engineering handbook. CorrOcean ASA, Oslo, Norway.

8. CZUJKO, J. and PAIK, J.K. (2015) A new method for accidental limit states design of thinwalled structures subjected to hydrocarbon explosion loads. Ships and Offshore Structures, Vol.10(5), pp.460-469.

9. DNVGL (2014) Safety principles and arrangements. DNV-OS-A101. Det Norske Veritas, Oslo, Norway.

10. FABIG (1996) Explosion resistant design of offshore structures. Technical Note 4. Fire and Blast Information Group, Berkshire, UK.

11. FLACS (2014) User's Manual for FLame ACcelation Simulator (FLACS) version 10.1. GexCon AS, Bergen, Norway.

12. FLACS2DYNA (2013) User's manual for an interface program between FLACS and ANSYS/LS-DYNA codes. The Korea Ship and Offshore Research Institute, Pusan National University, Busan, Korea.

13. HSE (2003) Pulse pressure testing of $1 / 4$ scale blast wall panels with connections. Research 
Report 124. Health and Safety Executive, London, UK.

14. ISO (2014) Petroleum and natural gas industries - specific retirements for offshore structures - part 3: topside structure. ISO 19901-3. International Standards Organization, Geneva, Switzerland.

15. LR (2014) Guideline for the calculation of probabilistic explosion loads. Report No. 104520/R1. Lloyd's Register, Southampton, UK.

16. NORSOK (2010) Risk and emergency preparedness assessment. NORSOK-Z003. Norway Standard, Lysaker, Norway.

17. OGP (2010) Risk assessment data directory: ignition probabilities. Report No. 434-6.1. International Association of Oil \& Gas Producers, London, UK.

18. Oil \& Gas UK (2006) Ignition probability review. Oil \& Gas UK, London, UK.

19. PEFERSEN, H.H. and MIDDHA, P. (2012) Modelling of vented gas explosions in the CFD tool FLACS. Transactions of Chemical Engineering, Vol.26, pp.357-362.

20. PAIK, J.K. (2011) Explosion and fire engineering on FPSOs (Phase III): nonlinear structural consequence analysis. Report No. EFEF-04. The Korea Ship and Offshore Research Institute, Pusan National University, Busan, Korea.

21. PAIK, J.K. (2015) Making the case for adding variety to goal-based standards. The Naval Architect, The Royal Institution of Naval Architects, January 2015, pp.22-24.

22. PAIK, J.K. and CZUJKO, J. (2010) Explosion and fire engineering on FPSOs (Phase II): definition of design explosion and fire loads. Report No. EFEF-03. The Korea Ship and Offshore Research Institute, Pusan National University, Busan, Korea.

23. PAIK, J.K., CZUJKO, J., KIM, S.J., LEE, J.C., Kim B.J., SEO, J.K. and HA, Y.C. (2014) A new procedure for the nonlinear structural response analysis of offshore installations in explosions. Proceedings of Society of Naval Architects and Marine Engineers Maritime Convention, Houston, TX, USA, 22-24 October.

24. VINNEM, J.E. (2007) Offshore risk assessment - principles, modelling and application of QRA studies. Springer, Stavanger, Norway. 


\section{APPENDIX}

Table A.1: Fifty selected gas dispersion scenarios

\begin{tabular}{|c|c|c|c|c|c|c|c|}
\hline \multirow{3}{*}{ No. } & \multicolumn{2}{|c|}{ Wind } & \multicolumn{5}{|c|}{ Leak } \\
\hline & \multirow{2}{*}{$\operatorname{Dir} .\left(^{\circ}\right)$} & \multirow{2}{*}{$\begin{array}{c}\text { Speed } \\
(\mathrm{m} / \mathrm{s})\end{array}$} & \multirow{2}{*}{$\begin{array}{c}\text { Rate } \\
(\mathrm{kg} / \mathrm{s})\end{array}$} & \multirow{2}{*}{ Dir. } & \multicolumn{3}{|c|}{ Position (m) } \\
\hline & & & & & $\mathrm{X}$ & $\mathrm{Y}$ & $\mathrm{Z}$ \\
\hline 1 & 67.8 & 5.9 & 2.17 & $-\mathrm{Y}$ & 8.5 & 6.1 & 0.6 \\
\hline 2 & 192.5 & 1.2 & 0.35 & $\mathrm{X}$ & 8.8 & 6.0 & 2.4 \\
\hline 3 & 202.1 & 2.4 & 0.09 & $-Z$ & 8.6 & 6.0 & 4.0 \\
\hline 4 & 49.5 & 2.0 & 0.93 & $\mathrm{Z}$ & 8.5 & 6.4 & 6.6 \\
\hline 5 & 59.1 & 3.2 & 5.81 & $-X$ & 11.7 & 9.0 & 0.4 \\
\hline 6 & 295.1 & 4.9 & 13.91 & $-X$ & 11.6 & 5.8 & 0.5 \\
\hline 7 & 83.1 & 2.9 & 0.31 & $-X$ & 14.4 & 12.0 & 3.1 \\
\hline 8 & 159.7 & 4.1 & 1.23 & $\mathrm{X}$ & 5.8 & 6.0 & 1.6 \\
\hline 9 & 238.4 & 2.8 & 1.35 & $-Z$ & 5.6 & 9.0 & 5.0 \\
\hline 10 & 331.0 & 5.6 & 3.24 & $-Z$ & 11.5 & 6.0 & 8.2 \\
\hline 11 & 222.1 & 2.6 & 7.75 & $-\mathrm{Y}$ & 11.4 & 3.6 & 4.3 \\
\hline 12 & 102.7 & 4.7 & 0.43 & $-X$ & 8.5 & 9.0 & 5.1 \\
\hline 13 & 125.2 & 1.8 & 0.13 & $-X$ & 17.7 & 3.0 & 3.5 \\
\hline 14 & 108.6 & 3.6 & 0.12 & $\mathrm{Y}$ & 2.5 & 3.0 & 2.6 \\
\hline 15 & 183.1 & 1.6 & 18.81 & $-\mathrm{Z}$ & 2.5 & 5.9 & 0.3 \\
\hline 16 & 232.8 & 0.8 & 0.70 & $\mathrm{Z}$ & 5.5 & 3.0 & 2.9 \\
\hline 17 & 286.1 & 1.3 & 0.28 & $\mathrm{Y}$ & 8.5 & 2.9 & 6.9 \\
\hline 18 & 317.0 & 1.9 & 9.15 & $Y$ & 8.4 & 3.3 & 3.8 \\
\hline 19 & 135.5 & 2.3 & 0.38 & $\mathrm{Y}$ & 5.5 & 12.1 & 8.2 \\
\hline 20 & 150.2 & 5.1 & 31.24 & $X$ & 6.1 & 2.9 & 4.6 \\
\hline 21 & 96.5 & 3.5 & 0.22 & $\mathrm{Z}$ & 5.5 & 6.0 & 0.9 \\
\hline 22 & 119.8 & 3.0 & 2.64 & $\mathrm{Y}$ & 11.5 & 3.3 & 7.4 \\
\hline 23 & 140.5 & 2.5 & 1.48 & $\mathrm{Z}$ & 11.5 & 6.0 & 8.1 \\
\hline 24 & 305.3 & 5.2 & 0.20 & $-X$ & 2.6 & 9.0 & 7.8 \\
\hline 25 & 277.8 & 3.9 & 1.12 & $\mathrm{Y}$ & 17.5 & 11.8 & 3.7 \\
\hline 26 & 173.8 & 3.1 & 6.67 & $-Y$ & 2.5 & 5.7 & 2.1 \\
\hline 27 & 227.3 & 3.4 & 0.25 & $-Z$ & 14.4 & 6.0 & 5.7 \\
\hline 28 & 216.9 & 6.1 & 0.85 & $\mathrm{Z}$ & 5.5 & 6.0 & 4.0 \\
\hline 29 & 270.3 & 2.9 & 2.92 & $-Y$ & 5.4 & 8.7 & 6.4 \\
\hline 30 & 207.0 & 3.8 & 0.17 & $\mathrm{Z}$ & 5.5 & 6.0 & 8.7 \\
\hline 31 & 169.1 & 1.5 & 0.10 & $-X$ & 5.6 & 9.0 & 1.7 \\
\hline 32 & 38.5 & 3.3 & 0.58 & $X$ & 5.6 & 9.0 & 7.3 \\
\hline 33 & 130.4 & 4.8 & 0.07 & $\mathrm{Y}$ & 2.5 & 12.1 & 6.8 \\
\hline 34 & 178.5 & 4.2 & 0.05 & $\mathrm{X}$ & 5.4 & 3.0 & 4.1 \\
\hline 35 & 75.7 & 4.3 & 0.52 & $-Z$ & 11.5 & 6.0 & 4.2 \\
\hline 36 & 197.3 & 7.0 & 1.79 & $\mathrm{Z}$ & 2.5 & 3.0 & 2.1 \\
\hline 37 & 9.6 & 4.4 & 1.97 & $-Y$ & 8.5 & 11.6 & 6.1 \\
\hline 38 & 25.6 & 5.4 & 0.64 & $-Y$ & 8.5 & 3.3 & 0.3 \\
\hline 39 & 349.0 & 0.5 & 0.15 & $\mathrm{Y}$ & 8.5 & 3.0 & 1.0 \\
\hline 40 & 256.5 & 3.7 & 1.02 & $-X$ & 14.7 & 9.0 & 3.3 \\
\hline 41 & 211.9 & 1.7 & 4.03 & $-Y$ & 8.5 & 8.9 & 6.3 \\
\hline 42 & 263.2 & 2.2 & 4.53 & $-X$ & 11.5 & 3.0 & 1.3 \\
\hline 43 & 164.4 & 4.6 & 1.63 & $-Z$ & 17.5 & 12.0 & 7.8 \\
\hline 44 & 244.2 & 6.5 & 0.06 & $\mathrm{Z}$ & 2.5 & 9.0 & 2.8 \\
\hline 45 & 250.2 & 2.1 & 0.47 & $X$ & 6.4 & 9.0 & 7.1 \\
\hline 46 & 155.0 & 1.0 & 5.11 & $-Y$ & 8.5 & 8.9 & 7.1 \\
\hline 47 & 114.3 & 2.7 & 11.07 & $-Z$ & 2.7 & 9.0 & 2.1 \\
\hline 48 & 187.8 & 8.1 & 2.39 & $\mathrm{X}$ & 2.4 & 6.0 & 5.7 \\
\hline 49 & 145.4 & 4.0 & 3.61 & $-Z$ & 14.5 & 9.0 & 7.2 \\
\hline 50 & 90.0 & 3.5 & 0.77 & $-X$ & 8.8 & 9.0 & 1.2 \\
\hline
\end{tabular}

Table A.2: Fifty selected gas explosion scenarios

\begin{tabular}{|c|c|c|c|c|}
\hline \multirow{2}{*}{ No. } & \multirow{2}{*}{ Size of gas cloud $\left(\mathrm{m}^{3}\right)$} & \multicolumn{3}{|c|}{ Centre of gas cloud (m) } \\
\hline & & $\mathrm{X}$ & $\mathrm{Y}$ & $\mathrm{Z}$ \\
\hline 1 & 624.1 & 5.8 & 3.3 & 4.9 \\
\hline 2 & 2.9 & 5.2 & 7.8 & 1.8 \\
\hline 3 & 342.6 & 5.6 & 4.7 & 4.6 \\
\hline 4 & 322.7 & 3.8 & 6.7 & 0.9 \\
\hline 5 & 518.6 & 10.2 & 10.1 & 6.3 \\
\hline 6 & 165.3 & 0.3 & 8.8 & 4.5 \\
\hline 7 & 363.6 & 12.4 & 11.8 & 4.1 \\
\hline 8 & 106.6 & 15.1 & 0.3 & 1.5 \\
\hline 9 & 85.9 & 4.2 & 10.6 & 3.1 \\
\hline 10 & 268.3 & 11.4 & 4.3 & 3.9 \\
\hline 11 & 409.1 & 4.6 & 8.7 & 3.5 \\
\hline 12 & 821.4 & 14.6 & 5.3 & 8.8 \\
\hline 13 & 285.6 & 7.6 & 9.8 & 4.0 \\
\hline 14 & 152.7 & 9.7 & 5.8 & 4.7 \\
\hline 15 & 66.6 & 1.4 & 8.3 & 9.4 \\
\hline 16 & 1059.6 & 7.2 & 7.1 & 3.7 \\
\hline 17 & 460.3 & 2.2 & 8.5 & 5.6 \\
\hline 18 & 303.7 & 15.7 & 5.6 & 5.2 \\
\hline 19 & 140.6 & 18.7 & 6.1 & 2.5 \\
\hline 20 & 128.9 & 2.8 & 2.0 & 8.3 \\
\hline 21 & 1570.5 & 14.2 & 2.5 & 3.2 \\
\hline 22 & 9.4 & 6.4 & 7.4 & 5.3 \\
\hline 23 & 96.1 & 10.6 & 11.3 & 6.8 \\
\hline 24 & 965.9 & 6.7 & 2.9 & 4.2 \\
\hline 25 & 665.9 & 11.6 & 10.3 & 1.6 \\
\hline 26 & 385.7 & 8.3 & 6.3 & 2.3 \\
\hline 27 & 178.3 & 9.0 & 4.1 & 2.4 \\
\hline 28 & 76.1 & 9.9 & 12.3 & 1.9 \\
\hline 29 & 433.9 & 4.9 & 9.0 & 6.0 \\
\hline 30 & 887.9 & 13.4 & 5.5 & 3.3 \\
\hline 31 & 1334.1 & 17.3 & 6.0 & 3.6 \\
\hline 32 & 191.9 & 3.3 & 13.1 & 1.2 \\
\hline 33 & 24.0 & 12.7 & 7.5 & 7.9 \\
\hline 34 & 31.8 & 8.8 & 4.5 & 2.8 \\
\hline 35 & 220.6 & 7.4 & 8.1 & 4.3 \\
\hline 36 & 551.0 & 10.9 & 7.2 & 3.4 \\
\hline 37 & 2050.7 & 9.2 & 6.6 & 6.2 \\
\hline 38 & 117.6 & 6.1 & 6.9 & 3.0 \\
\hline 39 & 1177.2 & 6.9 & 6.4 & 5.0 \\
\hline 40 & 763.3 & 7.9 & 9.6 & 2.0 \\
\hline 41 & 235.8 & 13.8 & 7.7 & 1.3 \\
\hline 42 & 586.0 & 9.5 & 3.6 & 7.6 \\
\hline 43 & 712.0 & 8.1 & 10.9 & 7.3 \\
\hline 44 & 205.9 & 10.4 & 9.4 & 2.7 \\
\hline 45 & 488.4 & 11.9 & 4.9 & 5.8 \\
\hline 46 & 251.7 & 12.2 & 5.1 & 2.6 \\
\hline 47 & 48.6 & 13.1 & 1.4 & 2.2 \\
\hline 48 & 16.4 & 11.1 & 9.2 & 7.0 \\
\hline 49 & 57.4 & 8.6 & 8.0 & 6.6 \\
\hline 50 & 40.0 & 16.3 & 3.8 & 5.5 \\
\hline
\end{tabular}


Table A.3: Maximum deflection at the centre of the blast wall and decks subjected to actual explosion loads (in mm)

\begin{tabular}{|c|c|c|c||c|c|c|c||c|c|c|c|}
\hline $\begin{array}{c}\text { Scenario } \\
\text { No. }\end{array}$ & $\begin{array}{c}\text { Blast } \\
\text { wall }\end{array}$ & $\begin{array}{c}\text { Upper } \\
\text { deck }\end{array}$ & $\begin{array}{c}\text { Process } \\
\text { deck }\end{array}$ & $\begin{array}{c}\text { Scenario } \\
\text { No. }\end{array}$ & $\begin{array}{c}\text { Blast } \\
\text { wall }\end{array}$ & $\begin{array}{c}\text { Upper } \\
\text { deck }\end{array}$ & $\begin{array}{c}\text { Process } \\
\text { deck }\end{array}$ & $\begin{array}{c}\text { Scenario } \\
\text { No. }\end{array}$ & $\begin{array}{c}\text { Blast } \\
\text { wall }\end{array}$ & $\begin{array}{c}\text { Upper } \\
\text { deck }\end{array}$ & $\begin{array}{c}\text { Process } \\
\text { deck }\end{array}$ \\
\hline 1 & 51.8 & 12.3 & 21.8 & 18 & 25.7 & 4.8 & 11.7 & 35 & 25.2 & 6.3 & 15.6 \\
\hline 2 & 1.8 & 3.0 & 3.3 & 19 & 4.5 & 2.6 & 4.6 & 36 & 47.5 & 10.6 & 20.6 \\
\hline 3 & 50.0 & 10.3 & 22.0 & 20 & 7.7 & 1.6 & 3.4 & 37 & 327.5 & 180.0 & 353.3 \\
\hline 4 & 36.8 & 16.2 & 14.9 & 21 & 77.1 & 13.9 & 34.3 & 38 & 23.4 & 4.8 & 10.7 \\
\hline 5 & 216.0 & 118.0 & 198.3 & 22 & 4.1 & 0.8 & 1.5 & 39 & 320.0 & 46.9 & 252.0 \\
\hline 6 & 5.2 & 2.5 & 5.0 & 23 & 11.6 & 7.4 & 11.0 & 40 & 190.0 & 27.9 & 91.8 \\
\hline 7 & 41.5 & 25.8 & 22.0 & 24 & 54.3 & 13.7 & 10.7 & 41 & 15.9 & 9.1 & 11.5 \\
\hline 8 & 4.7 & 1.5 & 2.6 & 25 & 168.0 & 32.5 & 101.0 & 42 & 82.6 & 17.2 & 47.5 \\
\hline 9 & 14.0 & 3.1 & 6.0 & 26 & 51.0 & 9.3 & 25.0 & 43 & 308.0 & 263.0 & 370.0 \\
\hline 10 & 30.2 & 6.4 & 14.2 & 27 & 23.3 & 6.6 & 14.3 & 44 & 30.5 & 9.0 & 20.1 \\
\hline 11 & 74.0 & 13.9 & 38.1 & 28 & 10.4 & 4.7 & 6.1 & 45 & 139.0 & 23.8 & 83.1 \\
\hline 12 & 154.0 & 28.6 & 252.0 & 29 & 115.0 & 19.5 & 56.2 & 46 & 29.2 & 7.6 & 15.6 \\
\hline 13 & 40.8 & 9.1 & 25.7 & 30 & 156.0 & 16.3 & 38.9 & 47 & 7.8 & 2.4 & 4.0 \\
\hline 14 & 24.5 & 7.3 & 16.1 & 31 & 72.1 & 10.2 & 29.3 & 48 & 8.4 & 4.4 & 8.1 \\
\hline 15 & 2.1 & 0.8 & 1.2 & 32 & 22.2 & 8.2 & 11.7 & 49 & 21.7 & 4.8 & 7.4 \\
\hline 16 & 224.0 & 25.4 & 91.6 & 33 & 12.3 & 5.2 & 10.2 & 50 & 11.7 & 2.5 & 5.8 \\
\hline 17 & 27.2 & 4.8 & 10.9 & 34 & 10.1 & 3.9 & 7.1 & & & & \\
\hline
\end{tabular}

Table A.4: Maximum plastic strain at the blast wall, frames and column subjected to actual explosion loads (in \%)

\begin{tabular}{|c|c|c|c|c|c|c|c|c|}
\hline \multirow{2}{*}{ Scenario No. } & \multicolumn{3}{|c|}{ Blast wall } & \multicolumn{2}{c|}{ Upper deck } & \multicolumn{2}{c|}{ Process deck } & Column \\
\cline { 2 - 9 } & A & B & C & D & E & F & G & H \\
\hline 1 & - & - & - & - & - & - & - & 0.94 \\
\hline 3 & - & - & - & - & - & - & - & 0.95 \\
\hline 4 & - & - & - & - & - & - & - & 0.44 \\
\hline 5 & 0.40 & 3.98 & 2.16 & 1.75 & 0.71 & 1.56 & 1.14 & 3.95 \\
\hline 7 & - & - & - & - & - & - & - & 0.45 \\
\hline 10 & - & - & - & - & - & - & - & 0.10 \\
\hline 11 & - & 0.09 & - & - & - & - & - & 1.58 \\
\hline 12 & 0.05 & 3.11 & 1.22 & 0.17 & - & 2.18 & 1.87 & 2.11 \\
\hline 13 & - & - & - & - & - & - & - & 0.43 \\
\hline 14 & - & - & - & - & - & - & - & 0.09 \\
\hline 16 & 0.43 & 2.02 & 0.32 & 0.16 & - & 0.21 & 0.02 & 4.23 \\
\hline 17 & - & - & - & - & - & - & - & 0.19 \\
\hline 18 & - & - & - & - & - & - & - & 0.06 \\
\hline 21 & - & 0.11 & - & - & - & - & - & 1.32 \\
\hline 23 & - & - & - & - & - & - & - & 0.44 \\
\hline 24 & - & - & - & - & - & - & - & 0.50 \\
\hline 25 & - & 0.84 & 0.24 & - & - & 0.11 & 0.07 & 2.36 \\
\hline 26 & - & - & - & - & - & - & - & 0.56 \\
\hline 27 & - & - & - & - & - & - & - & 0.28 \\
\hline 29 & - & 0.92 & 0.14 & 0.13 & - & 0.10 & - & 2.28 \\
\hline 30 & - & 0.94 & 0.23 & - & - & - & - & 2.31 \\
\hline 31 & - & 0.14 & - & - & - & - & - & 1.28 \\
\hline 32 & - & - & - & - & - & - & - & 0.15 \\
\hline 35 & - & - & - & - & - & - & - & 0.16 \\
\hline 36 & - & - & - & - & - & - & - & 0.25 \\
\hline 37 & 0.71 & 6.15 & 1.83 & 0.01 & 0.16 & 4.18 & 0.84 & 3.38 \\
\hline 38 & - & - & - & - & - & - & - & 0.05 \\
\hline 39 & 0.08 & 2.36 & 0.79 & 0.18 & - & 1.78 & 1.70 & 4.04 \\
\hline 40 & - & 1.23 & 0.36 & 0.13 & - & 0.15 & 0.03 & 2.36 \\
\hline 42 & - & 0.41 & 0.03 & - & - & - & - & 1.83 \\
\hline 43 & 1.76 & 7.26 & 3.15 & 2.48 & 2.00 & 5.36 & 1.21 & 4.56 \\
\hline 44 & - & - & - & - & - & - & - & 0.17 \\
\hline 45 & - & 1.51 & 0.25 & 0.12 & - & 0.19 & 0.02 & 2.46 \\
\hline 46 & - & - & - & - & - & - & - & 0.08 \\
\hline & - & - & - & - & - & & \\
\hline
\end{tabular}

*Note: There is no plastic strain in the un-noted scenarios in Table A.4. 